\title{
Estimating the Role of SST in Atmospheric Surface Wind Variability over the Tropical Atlantic and Pacific
}

\author{
INGO RICHTER AND TAKESHI DOI \\ Application Laboratory, Japan Agency for Marine-Earth Science and Technology, Yokohama, Japan
}

(Manuscript received 23 July 2018, in final form 19 March 2019)

\begin{abstract}
The influence of sea surface temperature (SST) on interannual surface wind variability in the tropical Atlantic and Pacific is estimated using sensitivity experiments with the SINTEX-F GCM and the ensemble spread in a nine-member control simulation. Two additional estimates are derived for both SINTEX-F and the ERA-Interim reanalysis using regression analysis and singular value decomposition. All methods yield quite consistent estimates of the fraction of surface wind variability that is determined by SST and therefore potentially predictable. In the equatorial Atlantic, analysis suggests that for the period 1982-2014 approximately $2 / 3$ of surface zonal wind variability in boreal spring and early summer is potentially predictable, while $1 / 3$ is due to noise. Of the predictable component, up to about $35 \%$ may be driven from outside the tropical Atlantic, suggesting an important role for remote forcing and a diminished one for local feedbacks. In the northern tropical Atlantic, only $30 \%$ of boreal winter variability is predictable, most of which is forced from the Pacific. This suggests a minor role for local coupled air-sea feedbacks. For the equatorial Pacific, the results suggest high predictability throughout the year, most of which is due to local SST, with the tropical Atlantic only playing a minor role in boreal summer. In the tropical Atlantic, atmospheric internal variability is strongly dependent on the presence of deep convection, which, in turn, is related to mean SST. A similar, but weaker, state dependence of internal variability is evident in the tropical Pacific.
\end{abstract}

\section{Introduction}

While seasonal climate prediction systems based on general circulation models have improved substantially over the last few decades it appears that there remains room for improvement. This was underscored by the broad agreement of dynamical forecasts in June 2014 for a Pacific El Niño event toward the end of the year that failed to materialize (McPhaden 2015; Imada et al. 2016; Zhu et al. 2016; Chiodi and Harrison 2017). Expectations for further improvement might be even higher in the equatorial Atlantic where models are still struggling to beat persistence forecasts (Richter et al. 2018). This expectation of improvement is based not only on the current relatively poor prediction skill but also on the severe biases that continue to plague general circulation models (GCMs) in the region (Davey et al. 2002; Richter and Xie 2008; Richter et al. 2014a). The underlying assumption is that mean state errors (biases) negatively affect a model's ability to reproduce observed variability patterns and that this, in turn, deteriorates

\footnotetext{
Corresponding author: Ingo Richter, richter@jamstec.go.jp
}

prediction skill. Few studies, however, have explicitly tested this assumption and the results tend to be not clear cut [e.g., Manganello and Huang 2009; Del Sole and Shukla 2010; Lee et al. 2010; Magnusson et al. 2013; see Richter et al. (2018) for a discussion of those results]. A recent study by Kumar and Zhu (2018), on the other hand, suggests that differences in SST prediction skill across the tropics are due to inherent predictability limits rather than model error, while Richter et al. (2018) showed some evidence that sea surface temperature biases in the tropical Atlantic have a relatively small impact on a GCM's ability to reproduce the observed variability of surface winds and precipitation. Evidence pointing in a similar direction comes from an earlier study by Richter et al. (2014a), who showed that some coupled ocean-atmosphere GCMs from phase 5 of the Coupled Model Intercomparison Project (CMIP5) reproduced observed variability patterns of SST and surface wind in the equatorial Atlantic even though they suffered from severe biases in the region.

Apart from model biases there are several other factors that could contribute to the poor skill of current prediction models in the tropical Atlantic. One is 
insufficient initialization data, particularly for the oceanic component. Subsurface temperature changes are thought to play an important role in both equatorial Atlantic and Pacific variability and, for the latter, it has been shown that initializing the three-dimensional ocean state facilitates successful prediction ( $\mathrm{Ji}$ and Leetmaa 1997; Alessandri et al. 2010; Zheng and Zhu 2015). The tropical Atlantic Ocean is less well observed than its Pacific counterpart and so one might expect that additional skill can be gained through an enhanced observational network. This is supported by a study by Tompkins and Feudale (2010), who showed increased prediction skill by improving the ocean initialization data only.

While ocean initialization problems can, at least in theory, be overcome there is another potential obstacle that most likely cannot: atmospheric internal variability. In the case of El Niño-Southern Oscillation (ENSO) it is generally held that atmospheric internal variability plays some role in the initialization and intensification of events, such as through westerly wind bursts (Moore and Kleeman 1999; Lengaigne et al. 2004; Eisenman et al. 2005; Levine and Jin 2010). The overall development of events, on the other hand, is thought to rely on coupled air-sea feedbacks (e.g., Neelin et al. 1998), in which the slowly evolving oceanic component reins in atmospheric noise. (Note that for the purposes of our study we use the terms "atmospheric internal variability" and "noise" interchangeably. What constitutes noise certainly depends on the time scale of interest. For our purposes, it is variability on intraseasonal and shorter time scales.) These coupled feedbacks are often conceptualized in terms of the Bjerknes feedback loop, which can be broken down into three components (Keenlyside and Latif 2007): 1) surface wind anomalies over the western basin lead to a readjustment of the equatorial thermocline; 2) thermocline anomalies in the central and eastern equatorial basin lead to local SST anomalies; and 3) SST anomalies in the central and eastern basin reinforce the initial surface wind anomalies. To what extent this feedback loop is operational in the equatorial Atlantic is still debated with some studies indicating a dominant role (Keenlyside and Latif 2007; Deppenmeier et al. 2016; Dippe and Greatbatch 2017) and others a less prominent one (Zebiak 1993; Richter et al. 2014b; Nnamchi et al. 2015; Richter et al. 2017).

The extent to which atmospheric internal variability influences the tropical Atlantic has important consequences. Atmospheric internal variability is inherently unpredictable at the time scales of interest and thus the greater its role in the equatorial Atlantic the smaller the prospect of improving prediction skill there. In other words, it might turn out that the poor prediction skill in the tropical Atlantic is due to inherent predictability limits rather than model biases. This would have profound implications regarding the priority of bias reduction.

In addition to atmospheric internal variability, misrepresentation of remote influences can be a factor deteriorating prediction skill. It has been known for some time that ENSO, through atmospheric teleconnections, has some influence on tropical Atlantic SST variability (Enfield and Mayer 1997; Latif and Grötzner 2000; Huang et al. 2002; Huang 2004), although the link is not straightforward (Chang et al. 2006; Lübbecke and McPhaden 2012; Richter et al. 2013; Lee et al. 2008; Amaya and Foltz 2014) and may be subject to low-frequency modulation (Martín-Rey et al. 2018). In recent years, several studies have suggested that tropical Pacific SST variability, in turn, is influenced by the equatorial Atlantic through atmospheric teleconnections [Wang 2006; RodríguezFonseca et al. 2009; Ding et al. 2012; Keenlyside et al. 2013; Sasaki et al. 2014; Terray et al. 2016; Kajtar et al. 2017; see also the review by Kucharski et al. (2016)] and by the northern tropical Atlantic (Ham et al. 2013; Wang et al. 2017). Some authors even suggest that the tropical Atlantic may have played a large role in the relatively cool eastern tropical Pacific SST during the period 1997-2012 (McGregor et al. 2014; Li et al. 2016; Kosaka 2018), which has been associated with the deceleration of global surface temperature warming (Kosaka and Xie 2013). Given these potential links it is also interesting to ask to what extent the tropical Pacific, through atmospheric processes (Alexander et al. 2002), may contribute to variability in the tropical Atlantic, and vice versa.

The main goal of the present study is to estimate the internal atmospheric contribution to tropical Atlantic variability, particularly in the equatorial region, and thereby shed some light on the inherent predictability of the region. We will focus on the variability of the surface wind, because it dominates dynamic forcing of the ocean circulation and plays a large role in the thermodynamic forcing through its influence on latent and sensible heat fluxes. To put our results into perspective, we will compare them with the equatorial Pacific. Furthermore, we attempt to examine the relative contributions of tropical Atlantic and tropical Pacific SST anomalies in generating surface wind variability in our regions of interest. To the best of our knowledge, a systematic study of this kind has not been published in the literature yet. We stress that our aim is not to examine coupled air-sea feedbacks per se but only their relative roles compared to atmospheric internal variability. 
Our main tool will be dedicated sensitivity tests with one particular GCM, the SINTEX-F. A description of the model and the setup of the sensitivity experiments are given in section 2. Atmospheric internal variability in the tropical Atlantic will be assessed in section 3. This will include an assessment of remote influences from the Pacific. For comparison, we also analyze the contribution of atmospheric internal variability to the tropical Pacific in section 4, and assess the potential influence from the Atlantic. In section 5 we examine how mean state biases influence internal variability. A summary and conclusions are given in section 6 .

\section{Model description and methods}

\section{a. Model description}

The present study uses the SINTEX-F GCM to conduct sensitivity tests with prescribed SST distributions. The model was developed under a European UnionJapan collaboration project (Luo et al. 2003) and is based on the European SINTEX model (Gualdi et al. 2003). The version used here consists of the ECHAM 4.6 AGCM (Roeckner et al. 1996), the OPA 8.2 oceanic GCM (OGCM; Madec et al. 1998), and the OASIS 2.4 coupler (Valcke et al. 2000). The atmospheric resolution is T106 (approximately $1.1^{\circ}$ ), with 19 vertical levels, 4 to 5 of which are inside the planetary boundary layer. The oceanic resolution is $2^{\circ} \times 2^{\circ}$ with the meridional resolution increasing to $0.5^{\circ}$ at the equator. The OGCM has 31 vertical levels, 19 of which lie within the top $400 \mathrm{~m}$.

To achieve the desired SST distributions strong SST restoring (1-day time scale) is used, resulting in SST boundary conditions that are very similar to an AMIPtype simulation but may differ from observations on the order of $0.1 \mathrm{~K}$. Thus, while the model is run with both atmospheric and oceanic components active, SSTs can essentially not react to the atmospheric forcing, leading to an almost complete decoupling of atmosphere and ocean. (The benefit of performing decoupled atmosphereocean experiments, rather than AGCM only experiments, is that our experiments can be used to provide initial conditions for future predictability experiments.) Several experiments are conducted (see Table 1), each consisting of nine ensemble members, which are generated by perturbing the SST boundary conditions with random values of amplitude $0.01 \mathrm{~K}$. In the control experiment (CTRL) SSTs are restored to the Optimum Interpolation SST (OISST; Reynolds et al. 2002) observations from 1982 to 2014. In the CGL experiment, global SSTs are restored to the climatology of the 19822014 OISST observations so that there are essentially no SST anomalies in this experiment. In another experiment, CTA, climatological SSTs are prescribed in the
TABLE 1. SINTEX-F experiments analyzed in this study.

\begin{tabular}{|c|c|}
\hline Experiment & Explanation \\
\hline CTRL & $\begin{array}{l}\text { Observed SST (1982-2014) prescribed } \\
\text { over the global oceans }\end{array}$ \\
\hline CGL & $\begin{array}{l}\text { Observed monthly SST climatology } \\
\text { prescribed globally }\end{array}$ \\
\hline CTA & $\begin{array}{l}\text { Observed monthly SST climatology } \\
\text { prescribed over the tropical Atlantic } \\
\left(30^{\circ} \mathrm{S}-30^{\circ} \mathrm{N}\right)\end{array}$ \\
\hline СТP & $\begin{array}{l}\text { Observed monthly SST climatology } \\
\text { prescribed over the tropical Pacific } \\
\left(30^{\circ} \mathrm{S}-30^{\circ} \mathrm{N}\right)\end{array}$ \\
\hline Atl_bias & $\begin{array}{l}\text { Like CTRL but with SST bias from } \\
\text { coupled SINTEX-F simulation added } \\
\text { to tropical Atlantic }\left(30^{\circ} \mathrm{S}-30^{\circ} \mathrm{N}\right)\end{array}$ \\
\hline
\end{tabular}

tropical Atlantic only, from $30^{\circ} \mathrm{S}$ to $30^{\circ} \mathrm{N}$. SSTs elsewhere are restored to the same values as in CTRL. Also, $5^{\circ}$ meridional transition zones are used to gradually blend climatological and observed SSTs at the northern and southern edges of the tropical Atlantic. A further experiment, CTP, is analogous to CTA but restores SST to climatology in the tropical Pacific $\left(30^{\circ} \mathrm{S}-30^{\circ} \mathrm{N}\right)$ instead of the tropical Atlantic.

Figure 1 shows the SST variance in CTRL and illustrates the CTP and CTA areas, along with some averaging regions that will be used in sections 3 and 4 . The Niño-4 region $\left(5^{\circ} \mathrm{S}-5^{\circ} \mathrm{N}, 160^{\circ} \mathrm{E}-150^{\circ} \mathrm{W}\right)$ is used to study surface zonal wind variability because it is the region of the equatorial Pacific where variability tends to be highest. Likewise, the ATL4 region $\left(3^{\circ} \mathrm{S}-3^{\circ} \mathrm{N}, 45^{\circ}-\right.$ $20^{\circ} \mathrm{W}$ ) is where surface zonal wind variability in the equatorial Atlantic tends to be highest. The NTA region $\left(10^{\circ}-20^{\circ} \mathrm{N}, 40^{\circ}-10^{\circ} \mathrm{W}\right)$ features high SST variability in the northern tropical Atlantic, which has been associated with surface wind-induced mixing and latent heat flux variations.

One could argue that a cleaner experimental setup would be to prescribe SST distributions generated by the free-running fully coupled GCM itself. This would avoid problems that might arise from the imbalance between the wind climatology intrinsic to the model and that generated by the observed SST (e.g., Larson et al. 2017). It would also allow for longer time series than the observational record affords. Such an approach, however, would be problematic since the SST climatology of the free-running model is biased, particularly in the equatorial Atlantic (e.g., Richter et al. 2014a). As will be shown in section 5 , such mean state SST biases also affect the simulated atmospheric variability. Since our goal is to estimate the role of atmospheric noise in nature, rather than in the model world, we believe that SST distributions derived from observations are most appropriate for our purposes. 


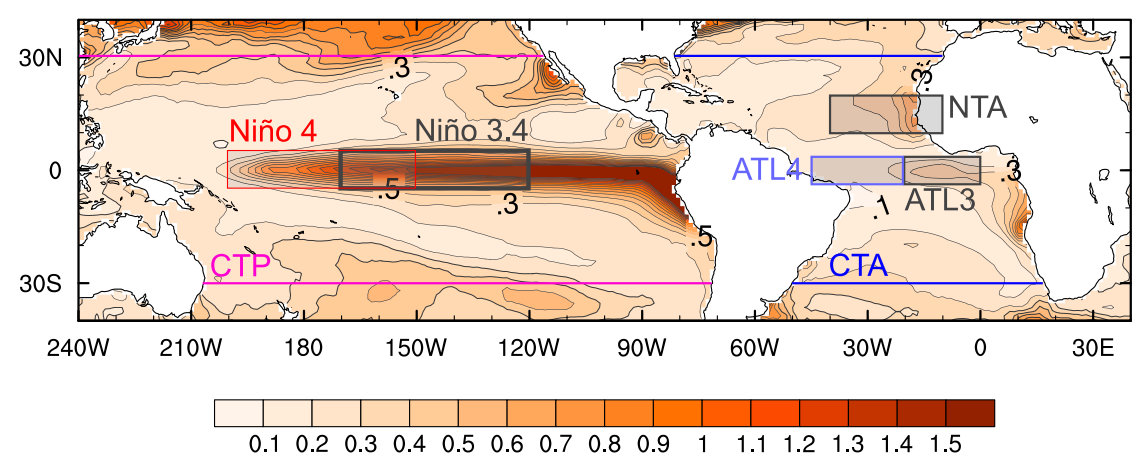

FIG. 1. Variance of SST (shading; $\mathrm{K}^{2}$ ) in the tropical Pacific and Atlantic. Several averaging areas used in this study are shown as boxes: Niño-4, Niño-3.4, NTA, ATL3, and ATL4. The pink and blue lines at $30^{\circ} \mathrm{S} / 30^{\circ} \mathrm{N}$ demarcate the area in which climatological SST are prescribed in experiments CTP and CTA, respectively.

\section{b. Methods for estimating noise}

Several methods are used to estimate the stochastic component of atmospheric variability in the tropical regions for our variables of interest, surface zonal wind and surface wind speed. In the first method, we calculate variance along the time dimension for experiment CGL and divide it by the corresponding variance in CTRL. For the second method, we calculate the ensemble spread (i.e., variance along the ensemble dimension) in CTRL based on the nine ensemble members. This allows estimating internal variability for each of the 396 months in the 1982-2014 simulation period. The resulting variance field can be used to calculate climatological values. In both methods, we stratify the calculation by calendar month. One concern regarding method 1 is whether the residual SST variability on the order of $0.1 \mathrm{~K}$ in CGL (see section 2a) could force significant wind variability and thus lead to an overestimate of atmospheric internal variability. The relatively good agreement between methods 1 and 2 to be shown later (see Figs. 2a and 9a) suggests that this is not a large factor. A concern regarding both methods 1 and 2 is whether the ensemble size is sufficient to characterize atmospheric variability. We have checked how estimates depend on ensemble size by subsampling ensemble members. The results (not shown) indicate that estimates are relatively robust for ensemble sizes greater than 4-5. We therefore believe that our results will not change much even if we used a larger ensemble.

Common to both of the above methods is that they can only be applied to model simulations. Observations afford neither multiple realizations nor fixed SST. To compare our results to observational estimates we use two additional methods. Method 3 relies on multiple linear regression analysis of climate indices using a priori knowledge. Surface zonal winds over the western equatorial Pacific, for example, are strongly influenced by SST in the central and eastern equatorial Pacific (Bjerknes 1969; Jin 1997). Further studies have linked equatorial Pacific winds to SST anomalies in the tropical Atlantic and Indian Oceans (Rodríguez-Fonseca et al. 2009; Izumo et al. 2010; Ham et al. 2013). We therefore reconstruct surface zonal wind anomalies over the western equatorial Pacific through multiple linear regression using three SST indices from the tropical ocean basins (more details of the method, including the indices used, will be given in section 3). The skill of this reconstruction should be inversely related to the strength of internal variability: the more noise there is in the system the less skillful the SST-based reconstruction will be. This method, of course, has many caveats but provides a way of estimating atmospheric noise from observations. For the models, we can validate the method by comparing with the first two methods.

Method 4 follows a similar approach as method 3 but dispenses with a priori knowledge by using singular value decomposition (SVD) of SST and surface winds. SVD is a statistical technique that seeks patterns of maximum covariability between two or more fields. Here we use the technique to find those tropical SST patterns that have the highest correlation with equatorial surface winds in the Pacific or Atlantic. This offers an alternative way of reconstructing surface wind anomalies that does not rely on the choice of SST indices.

Both methods 3 and 4 may be criticized because they cannot establish whether the atmosphere forces the ocean, or vice versa. One could envision a situation in which the ocean reacts to atmospheric forcing but does not feed back to the atmosphere; this is probably a good approximation for some midlatitude oceanic regions. For the tropics, and particularly the equatorial regions, however, we know that there is significant air-sea coupling. We also know that the atmosphere 
typically adjusts to SST forcing within one month (while the oceanic response, depending on the region, may take many months). This gives us some confidence in the regression and SVD estimates, although there is a possibility that these methods overestimate the predictable component.

The four methods described above allow us to analyze the relative contributions of signal and noise to a field $X$, so that we may write $X=X_{\text {signal }}+X_{\text {noise }}$, or $X=s+n$ for short. One may be interested in further separating this into local and remote contributions. For the equatorial Atlantic, for example, one may ask to what extent surface wind is controlled by local SST anomalies and to what extent it is controlled remotely, particularly from the Pacific. This is the motivation for the CTA and CTP experiments. In terms of the above equation, we can write $X=s+n=s_{\mathrm{loc}}+s_{\mathrm{rem}}+n_{\mathrm{loc}}+$ $n_{\text {rem }}$, where subscripts loc and rem stand for local and remote, respectively. Thus CTA gives an estimate of $s_{\text {rem }}$ for the tropical Atlantic (i.e., the contribution to tropical Atlantic wind variability from SST outside the region), and CTP an estimate of $s_{\text {rem }}$ for the tropical Pacific. The term $s_{\text {loc }}$ can then be calculated because we know $n_{\text {loc }}+n_{\text {rem }}$ from CGL. The method is certainly imperfect as it assumes that local and remote SST forcings linearly add up, while in reality they may interact. Furthermore, the observed SST distribution in a given basin will be partly shaped by other basins through atmospheric teleconnections. This imprint will remain even if SST anomalies are removed from the remote basin and may therefore contribute indirectly to wind variability. Our sensitivity tests may therefore underestimate the role of teleconnections. It should also be noted that none of the experiments allows separating the local and remote components of the noise. The above equation only lists those terms for conceptual consistency.

\section{Tropical Atlantic}

\section{a. Equatorial Atlantic}

In the equatorial Atlantic, observed surface zonal wind variability is concentrated in the west (e.g., Richter et al. 2014a), where it is most pronounced from March through June (MAMJ; black line in Fig. 2a). This peak is reproduced by the CTRL simulation but overestimated by a factor of roughly 2 . The excessive equatorial wind variability is typical for GCMs as shown in Richter et al. (2014a,b) and may be related to the excessive precipitation over tropical oceans (e.g., Richter et al. 2016). With climatological SST everywhere (experiment CGL) surface wind variability generally maintains its seasonality but, compared to
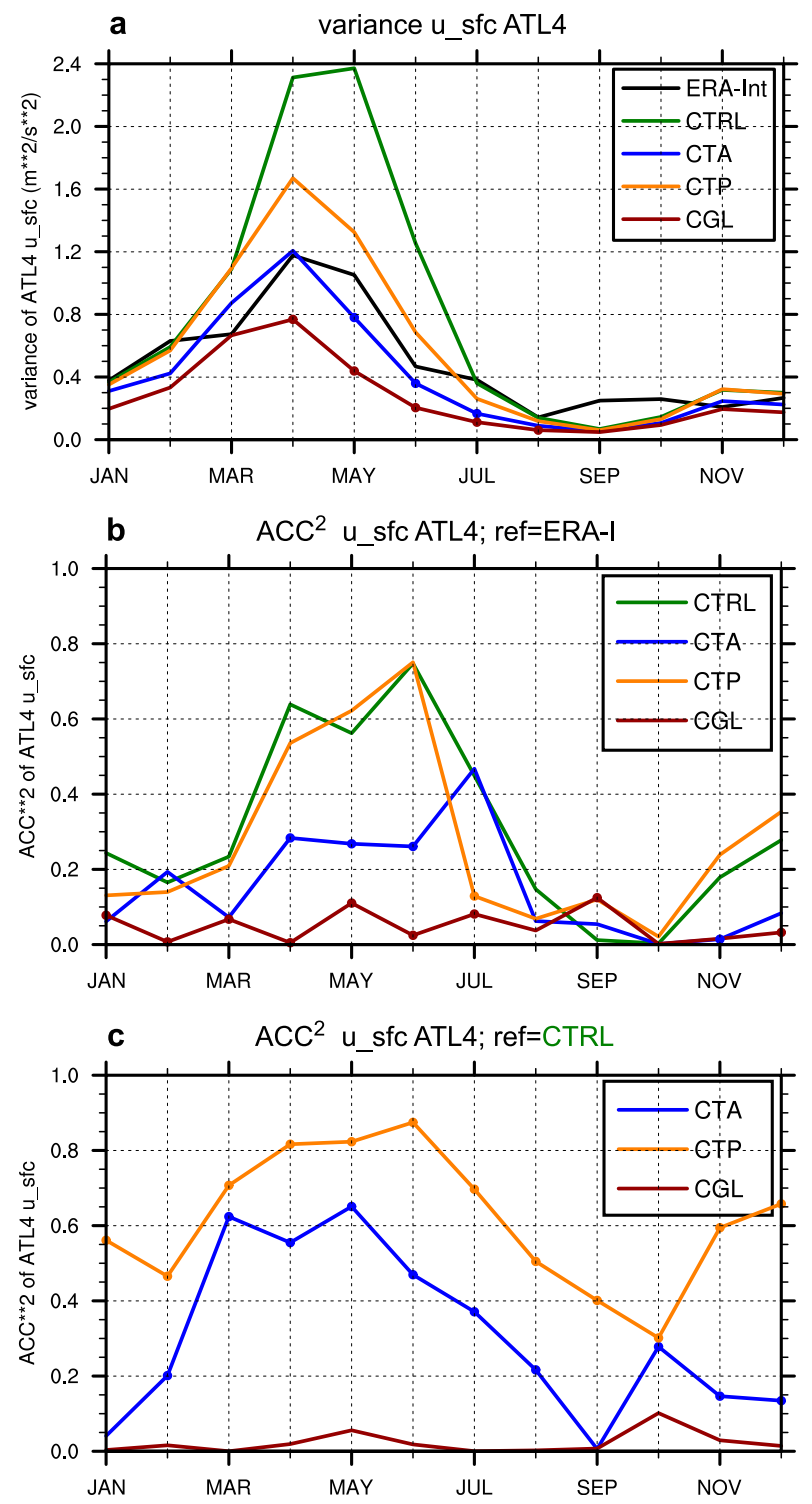

FIG. 2. Seasonally stratified values averaged over the ATL4 region. (a) Variance of surface zonal wind. (b) Squared anomaly correlation coefficient $\left(\mathrm{ACC}^{2}\right)$ with respect to the ERA-Interim. (c) $\mathrm{ACC}^{2}$ with respect to CTRL. The individual lines show the following SINTEX-F experiments: CTRL (green), CTA (blue), CTP (orange), and CGL (brown). The black line in (a) denotes the ERA-Interim. Values that are statistically at the $95 \%$ level are marked by filled circles. Significance is calculated relative to CTRL in (b) and relative to zero in (c).

CTRL variance decreases markedly. For MAMJ, the decrease relative to CTRL is $68 \%$. Taken at face value, this suggests that $32 \%$ of the MAMJ wind variability in the ATL4 region is due to atmospheric noise. This is certainly only a rough estimate because the noise and SST-driven signal may not add up linearly.

To examine the role of remote SST influences on ATL4 zonal wind variability we turn to the experiments 
with climatological SST in the Atlantic (CTA) and the Pacific (CTP). In CTA, variability also decreases markedly but is higher than in CGL. To quantify this influence, we first subtract the variance of the noise, as estimated from experiment CGL, from both CTRL and CTA and then calculate the relative difference between the two. For the ATL4 region during MAMJ this suggests that $73 \%$ of deterministic variability is due to local SST anomalies, with the remaining $27 \%$ due to remote SST anomalies.

In experiment CTP, ATL4 wind variability also decreases but less than in CTA. This suggests that tropical Pacific SST has considerable influence on ATL4 wind variability, although less than the local SST. Repeating the calculation above for CTP, we find that $63 \%$ of deterministic ATL4 variability is due to SST anomalies outside the tropical Pacific, including the tropical Atlantic. This would suggest that at most $63 \%$ of variability can be controlled by tropical Atlantic SST, which is less than the $73 \%$ estimated from experiment CTA. The discrepancy indicates that the uncertainty in our estimates of regional contributions is considerable.

To get an impression of the ability of the experiments to reproduce the observed surface wind anomalies we calculate the anomaly correlation coefficient (ACC) with respect to ERA-Interim (Fig. 2b). The squared ATL4 ACC $\left(\mathrm{ACC}^{2}\right)$ in CTRL is high from April through June (roughly around 0.65 , corresponding to an ACC of 0.8). CTA shows a marked drop in $\mathrm{ACC}^{2}$ that is significant at the $95 \%$ level from April through June, whereas CTP shows relatively small decreases, except in July.

The $\mathrm{ACC}^{2}$ can also be used to assess basin contributions to the deterministic component of ATL4 wind variability. For this purpose, the ACC is calculated with respect to the CTRL ensemble average, so as to minimize the noise. Even in the absence of tropical Atlantic SST anomalies (experiment CTA) the ATL4 winds are reproduced with an $\mathrm{ACC}^{2}$ of about $0.5-0.6$ (ACC $\sim 0.7-0.8$ ) during MAMJ. In CTP, the $\mathrm{ACC}^{2}$ is around $0.8(\mathrm{ACC} \sim 0.9$ ), while in CGL, as expected, it is close to zero.

We analyze the temporal evolution of westerly wind events in the equatorial Atlantic using composites. Our criterion for compositing is westerly surface wind anomalies averaged over the ATL4 region exceeding one standard deviation in the boreal spring (MAM) seasonal average. This criterion is applied to the individual ensemble members. In CTRL, there are 80 events in the nine ensemble runs matching this criterion. Note that westerly wind events in the equatorial Atlantic are neither necessary nor sufficient for the development of warm events (also called Atlantic Niños). Rather, they are one factor increasing the probability of occurrence. Other factors, such as off-equatorial heat content (Richter et al. 2013) and wave dynamics (Foltz and McPhaden 2010; Lübbecke and McPhaden 2012) have to be considered. This differs from the Pacific, where the link between westerly wind events and El Niños is much tighter (Richter et al. 2013). Accordingly, some of the selected years are not Atlantic Niño years, while some of the deselected ones are. This is the reason why the CTRL composite (Fig. 3a) shows only a weak warm ATL3 SST anomaly.

In the composite westerly wind event of CTRL, westerly winds gradually develop at the beginning of the calendar year, rapidly intensify in March, and peak in April. This is preceded by anomalously high precipitation in the south equatorial Atlantic (SEA; $10^{\circ}-$ $\left.4^{\circ} \mathrm{S}, 40^{\circ} \mathrm{W}-10^{\circ} \mathrm{E}\right)$. This relation of equatorial Atlantic winds to precipitation south of the equator was first noted in Richter et al. (2014a) and further explored in Richter et al. (2014b, 2017).

The composite event in CTA (Fig. 3b; based on 64 selected years that partially coincide with those in CTRL) has a smaller amplitude than CTRL but evolves qualitatively similarly, except that the wind decays already in May. SST anomalies are zero by design. In CTP (Fig. 3c; based on 58 selected years), the composite event has similar amplitude as in CTRL. Both CTA and CTP show a clear precipitation signal although it tends to coevolve with the wind anomalies rather than preceding them. Finally, in CGL (Fig. 3d; based on 47 selected years), the amplitudes are weakest but the coevolution of wind and precipitation indices remains.

We complement the index-based analysis above with composite horizontal maps averaged over the MAM peak season (Fig. 4). Some features in the tropical Atlantic are common to all four experiments (CTRL, CTA, CTP, CGL). There is an anomalous zonal gradient of sea level pressure (SLP) in the deep tropics with high pressure over South America and the western Atlantic, and low pressure over the eastern Atlantic and West Africa. The Atlantic ITCZ is shifted southward, as indicated by the meridional dipole in anomalous precipitation, and there are northwesterly wind anomalies over the equator consistent with this configuration. In the subtropics, there are anomalous high pressure centers both south and north of the equator. Except for CTP, these are complemented by similar pressure centers over the eastern subtropical Pacific.

A pronounced Atlantic-Pacific interbasin SLP gradient is evident in CTRL, CTA, and CGL. This feature has received some attention with regards to the Atlantic-Pacific connection (Wang 2006). 
a

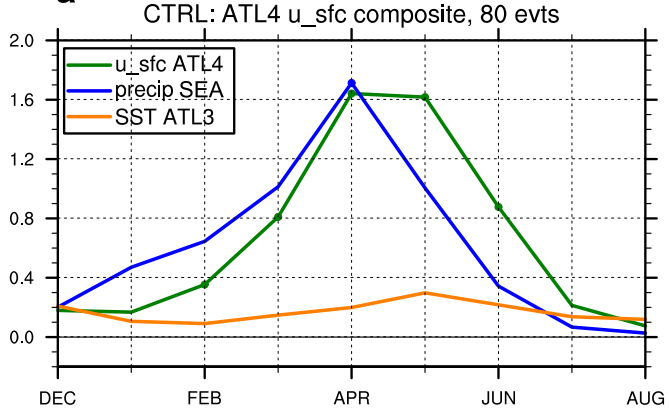

C

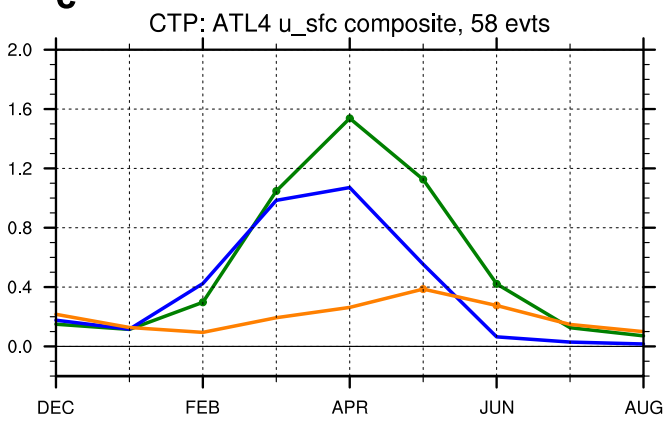

b

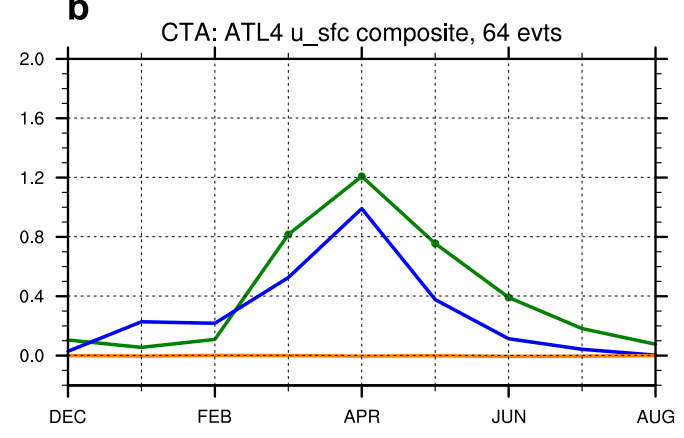

d

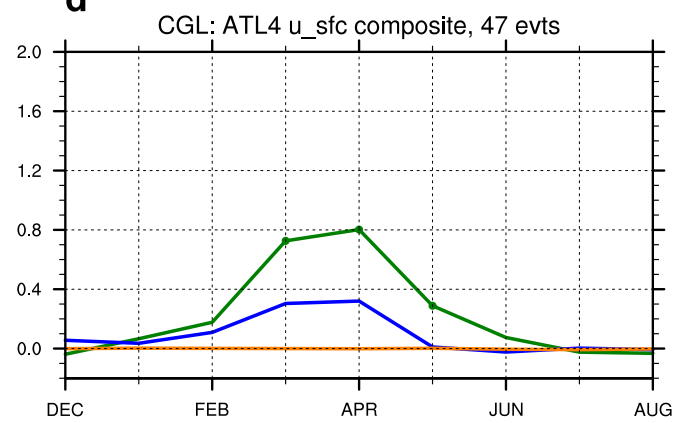

FIG. 3. Anomalies of ATL4 surface zonal wind (green line; $\mathrm{m} \mathrm{s}^{-1}$ ), SEA precipitation (blue line; $\mathrm{mm} \mathrm{day}^{-1}$ ), and ATL3 SST (orange line; K) composited on one standard deviation of MAM surface zonal wind in the ATL4 region. The individual panels show (a) CTRL, (b) CTA, (c) CTP, and (d) CGL. The number of events used for each composite is noted in the title of each panel. These events are selected from all ensemble members of a given experiment.

Accordingly, one might argue that the equatorial Atlantic westerlies are a consequence of the interbasin pressure gradient. This, however, is not supported by CTP, because there the interbasin SLP gradient is reversed while the westerly anomalies over the equatorial Atlantic are almost as strong as in CTRL. This suggests that the pronounced SLP anomalies in the subtropics and equatorial Pacific are not necessary for pronounced ATL4 wind events. In nature, the Pacific influence may still be important by contributing to the northern tropical Atlantic SST anomalies, which in turn promote the development of the tropical Atlantic SLP patterns seen in Fig. 4. This cannot be addressed in our experiments because the SSTs are prescribed.

The CTP experiment seems to suggest that the tropical Pacific SST anomalies are responsible for the large-scale SLP configuration in the tropics and subtropics. It is therefore puzzling that CGL, which has no SST anomalies anywhere, features an SLP configuration similar to CTRL and CTA, which do have tropical Pacific SST anomalies. The fact that the Atlantic and Indian Ocean SST anomalies (present in CTP) create a rather different SLP pattern seems to suggest that they are, to some extent, counteracting the Pacific influence.

\section{b. Northern subtropical Atlantic}

We focus on variability in the northern subtropical Atlantic, which has been shown to be influenced by the Pacific but has also been implicated in the meridional mode of tropical Atlantic variability. Both SST variability (Fig. 1) and surface wind speed variability (Fig. 6a) are high in the NTA region, which will be the focus of our analysis.

In the ERA-Interim the variance of NTA surface wind speed is highest in boreal winter, with a peak in February (Fig. 5a). This seasonality is consistent with the strong influence from ENSO (Enfield and Mayer 1997), which tends to peak during that season. CTRL reproduces the observed annual cycle except that the peak occurs in January and is somewhat less pronounced. CTA shows a slight decrease in boreal winter, which is not statistically significant. CTP and CGL show a more pronounced drop in the boreal winter variance but for these experiments, too, the differences from CTRL are not statistically significant. As in section $3 \mathrm{a}$ we estimate the deterministic component of the surface wind speed variance by subtracting the variance in CGL from that in the other experiments and then calculate the difference of CTA and CTP relative to CTRL. The calculation suggests 
a
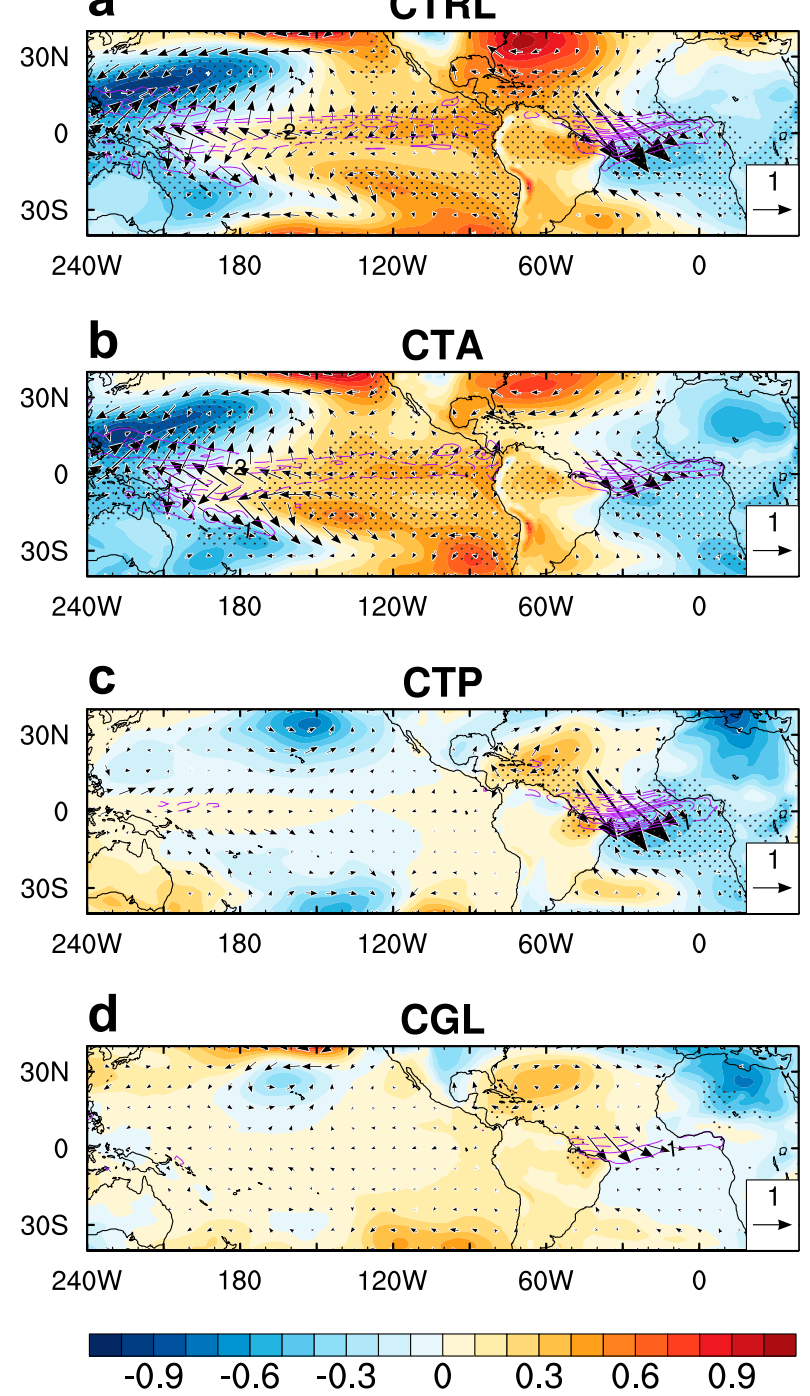

FIG. 4. Anomalies of SLP (shading; hPa), surface wind (vectors; reference $1 \mathrm{~m} \mathrm{~s}^{-1}$ ), and precipitation (contours; $\mathrm{mm} \mathrm{day}^{-1}$ ) composited on one standard deviation of MAM surface zonal wind in the ATL4 region (same criterion as in Fig. 3). The individual panels show (a) CTRL, (b) CTA, (c) CTP, and (d) CGL. Stippling indicates where the SLP anomalies are significant at the $95 \%$ level according to a $t$ test.

that $23 \%$ of deterministic DJF variance is controlled by tropical Atlantic SST. Since variance in CTP is lower than in CGL for the season of interest, the method yields unreasonable values greater than $100 \%$ for the deterministic component of variance controlled by tropical Pacific SST. This clearly suggests that the SST influences from different regions do not add up linearly here.

ACC analysis, performed as in section 3a, shows that the model's skill in reproducing observed wind speed variability in the NTA is relatively low (Fig. 5b). The $\mathrm{ACC}^{2}$ values in CTRL and CTA are around 0.2
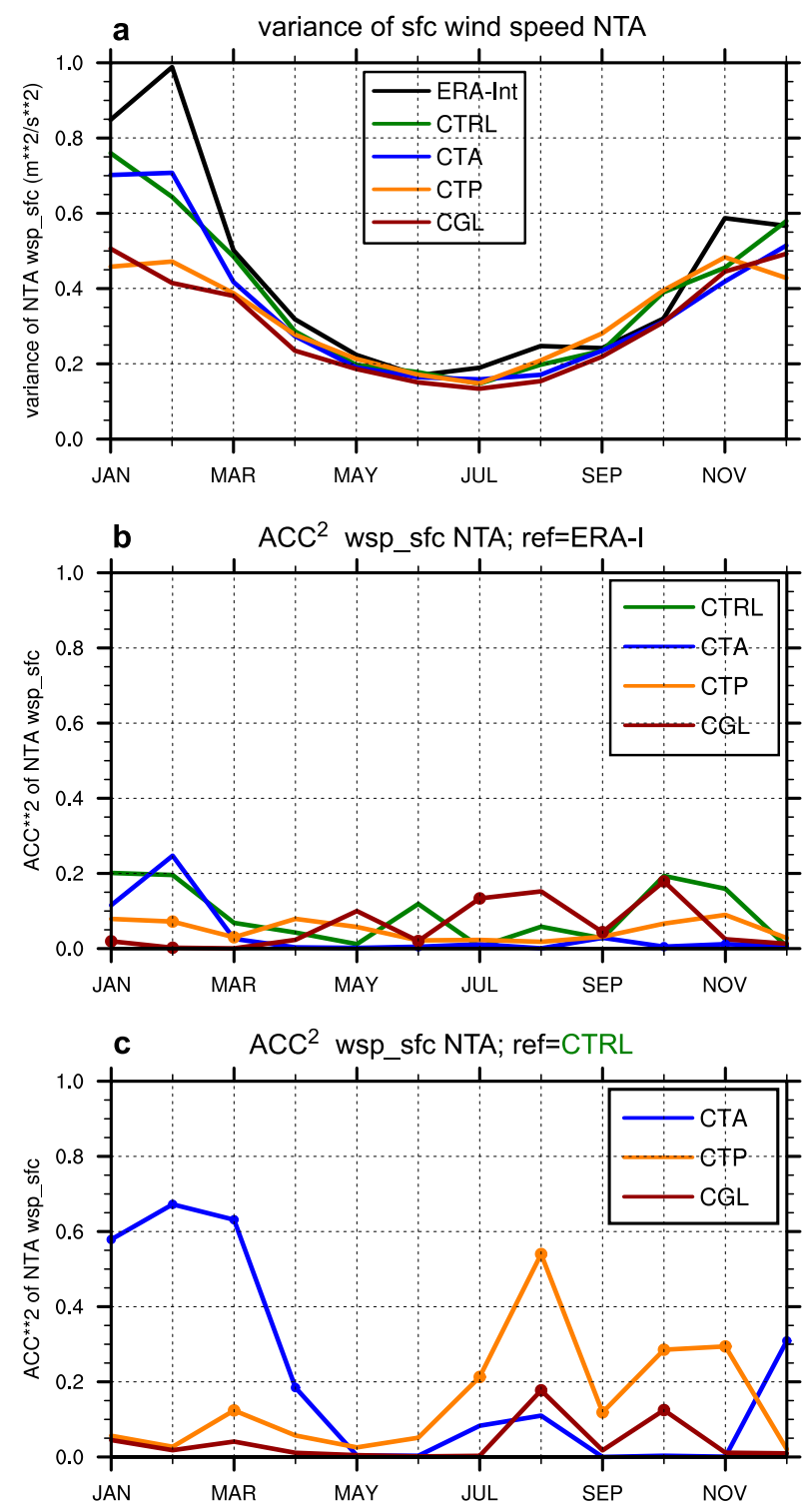

FIG. 5. As in Fig. 2, but for surface wind speed averaged over the NTA region.

(ACC 0.45) in January and February, and lower in most other months. The $\mathrm{ACC}^{2}$ with respect to CTRL shows strong seasonality in CTA and CTP (Fig. 5c). CTA is above 0.6 from January through March, while CTP is close to zero during the same period. The results suggest that NTA winds in January and February are mostly controlled by tropical Pacific SST. In December, on the other hand, both CTA and CTP have very low skill, indicating that the high NTA wind variability during that month is mostly due to atmospheric noise or, alternatively, that the nine-member mean is not sufficient to determine the signal.

The spatial structure of surface wind speed variance during DJF is shown in Fig. 6. Subtropical maxima in 
a

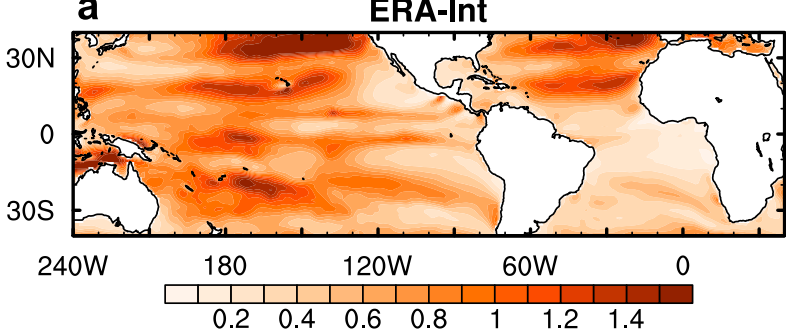

b
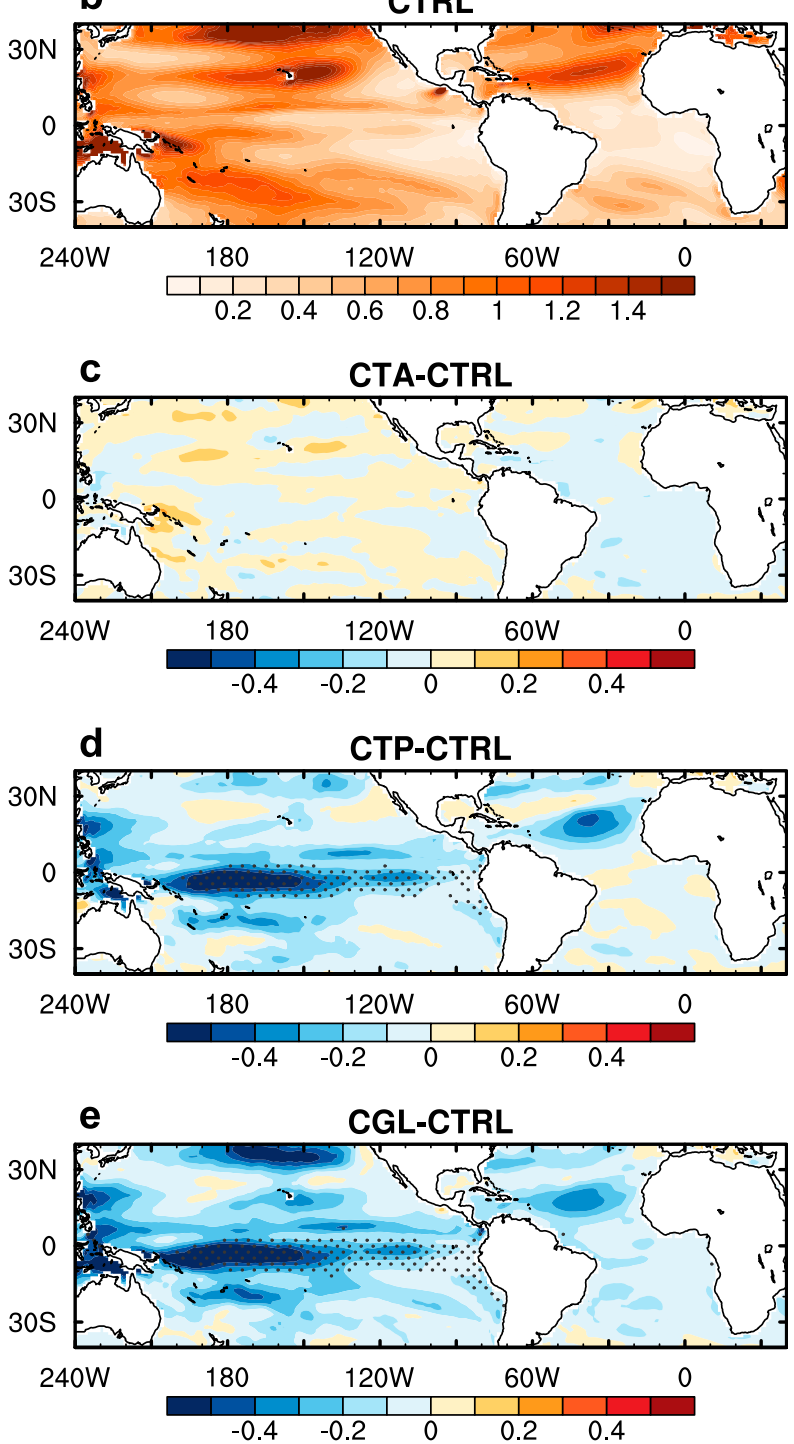

FIG. 6. Variance of surface wind speed (shading; $\mathrm{m}^{2} \mathrm{~s}^{-2}$ ) for (a) ERA-Interim, (b) CTRL, (c) CTA minus CTRL, (d) CTP minus CTRL, and (e) CGL minus CTRL. In (c)-(e), differences that are significant at the $95 \%$ level are indicated by stippling.

both the Pacific and Atlantic are evident in the reanalysis data (Fig. 6a). It is also evident that, in the tropical Atlantic, the northern maximum is much more pronounced than the southern one. CTRL reproduces
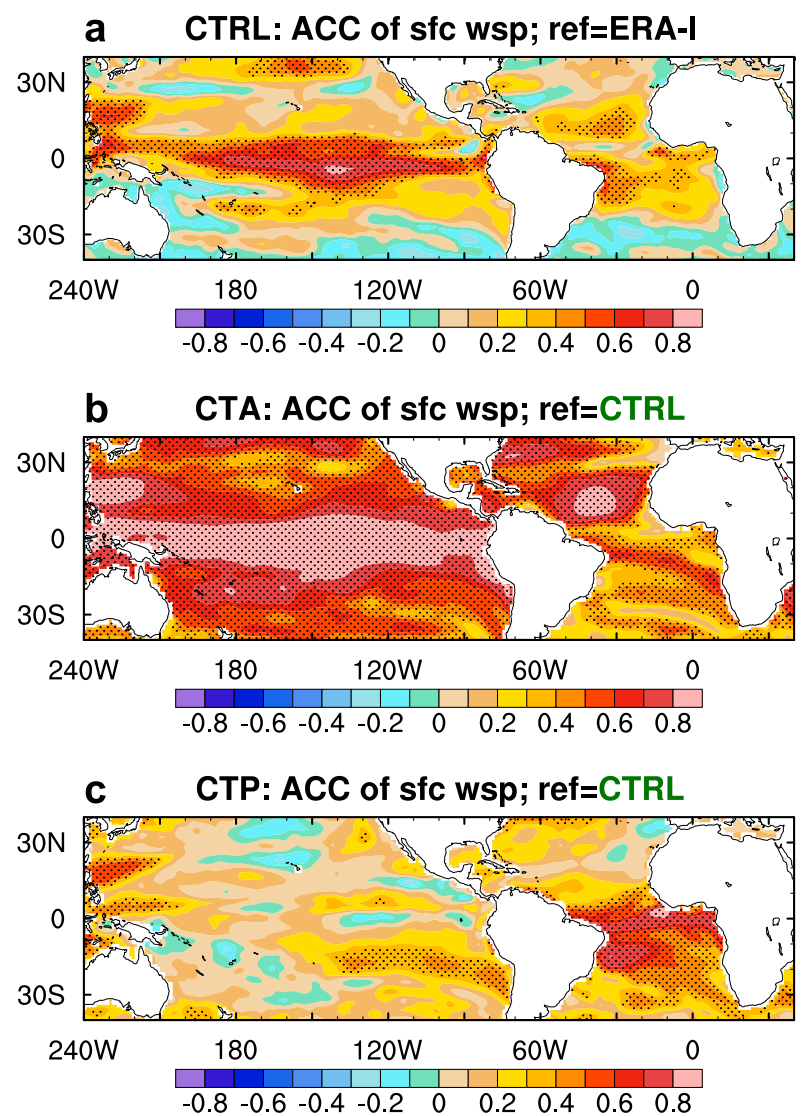

FIG. 7. ACC of surface wind speed in (a) CTRL, (b) CTA, and (c) CTP. ACC is calculated with respect to ERA-Interim in (a), and with respect to CTRL in (b) and (c). Stippling indicates differences that are significant at the $95 \%$ level.

these features fairly well (Fig. 6b). The changes in CTA are small and not significant at the 95\% level (Fig. 6c). There is a slight decrease in the northern tropical Atlantic (also illustrated by Fig. 5) and an increase in the western tropical Pacific. In CTP (Fig. 6d), the decrease of variance in the northern tropical Atlantic is more distinct and, as expected, there are statistically significant decreases in the equatorial Pacific. The decrease in CGL is similar to that in CTP but somewhat more pronounced in the northern Pacific from $30^{\circ}$ to $40^{\circ} \mathrm{N}$ and less pronounced in the northern subtropical Atlantic (Fig. 6e).

We conclude this subsection by assessing horizontal maps of surface wind speed ACCs for January-March (Fig. 7), when the ACC is highest (Fig. 5c). With respect to the ERA-Interim reanalysis, CTRL has some moderate skill in the subtropical Atlantic (Fig. 7a), with some ACC values above 0.4 in the NTA region. Values in the equatorial Pacific are high, as expected. For CTA and CTP, we calculate the ACC with respect to CTRL. When tropical Atlantic SST anomalies are removed 
(experiment CTA) the ACC is high in the tropical Pacific but also in the northern tropical Atlantic. Some statistically significant ACC is also seen in the southeastern tropical Atlantic. In contrast, CTP shows almost no skill in the NTA and tropical Pacific regions. There is, however, relatively good skill in the equatorial and southern tropical Atlantic. The overall impression is that the northern tropical Atlantic is dominated by tropical Pacific SSTs, while the equatorial and southern tropical Atlantic are more dependent on local SSTs. This extends to MAM as well, as we have confirmed (not shown). The fact that the Pacific-to-Atlantic influence varies depending upon region is consistent with previous studies (e.g., Enfield and Mayer 1997; Keenlyside and Latif 2007).

While there remains substantial uncertainty due to potential model dependency and other factors, the results from our sensitivity tests indicate that surface wind variability in the northern tropical Atlantic is dominated by tropical Pacific SSTs. The results also suggest that there is a large stochastic component to the wind variability, which is, to some extent, consistent with results from other studies (e.g., Chang et al. 2001). A positive coupled feedback involving surface wind speed, evaporation, and SST (the so-called WES feedback) has been suggested to play a role in subtropical variability in general (Xie and Philander 1994) and in the meridional mode of tropical Atlantic variability in particular (Chang et al. 1997). Although our approach can only address one component of this feedback (namely, the atmospheric response to SST anomalies), the results suggest that the WES feedback only plays a minor role in the NTA variability. For the most part, variability in this particular region appears to be forced from the Pacific, which is also supported by a recent study from García-Serrano et al. (2017). The WES feedback may play a more important role closer to the equator to the southwest of the NTA region, as indicated by a recent study (Amaya et al. 2017).

\section{c. Comparison with alternative estimates of internal variability}

We estimate the predictable fraction of surface zonal wind in the ATL4 region by using the four methods outlined in section $2 \mathrm{~b}: 1$ ) the CGL experiment, 2) the ensemble spread in CTRL, 3) multiple linear regression, and 4) SVD analysis. In methods 1 and 2 we use seasonally stratified variances to calculate the predictable fraction. In method 3 we areaaverage SST over the ATL3, ATL4, and Niño-3.4 regions (see Fig. 1 for area definitions) and perform a seasonally stratified multiple linear regression on the ATL4 surface zonal wind. The squared ACC between the fit and the reference data (ERA-Interim

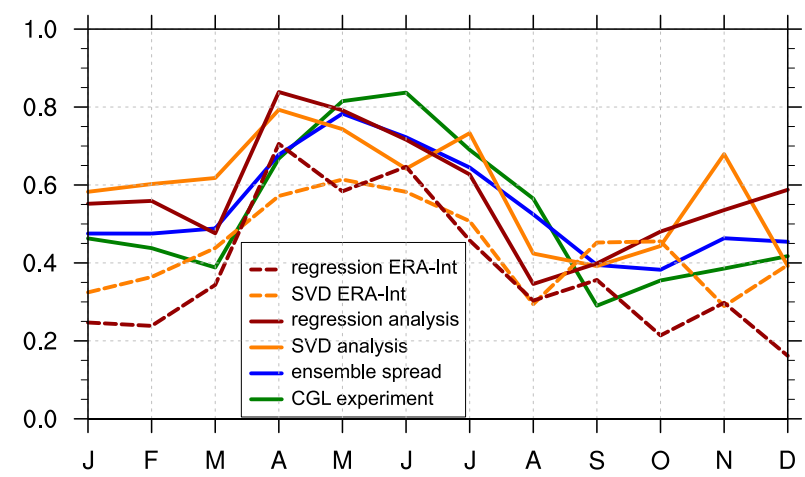

FIG. 8. Comparison of four methods for estimating the predictable fraction of surface zonal wind variability in the ATL4 region: CGL experiment (green line), ensemble spread in CTRL (blue line), SVD reconstruction of surface wind (orange line), and regression analysis (brown line). The solid lines denote estimates from SINTEX-F experiments, while the dashed lines denote estimate from the ERA-Interim (SVD and regression only).

reanalysis) is our estimate of the predictable fraction. In the fourth method, we perform a seasonally stratified SVD analysis between surface zonal wind in the equatorial Atlantic region $\left(5^{\circ} \mathrm{S}-5^{\circ} \mathrm{N}\right)$ and global SST to find the patterns of highest covariability. We then project global SST on the first three singular vectors of SST. The resulting expansion coefficient time series are multiplied with the corresponding singular vectors of surface zonal wind to reconstruct the wind field in the equatorial Atlantic. This wind field is averaged over the ATL4 region to obtain our index of interest. The idea is to extract the maximum amount of information contained in the SST field with regards to equatorial Atlantic winds.

The four methods are compared in Fig. 8. The CGL experiment gives the most optimistic estimate of predictability in late spring and summer, with a maximum close to 0.85 in June. The ensemble spread method yields qualitatively similar results but estimates tend be somewhat lower. The regression analysis also suggests lower predictability than method 1 from May through August, but higher values in other months. The estimate from the SVD analysis most closely resembles that from the regression analysis. Overall, the different methods agree relatively well, indicating highest predictability from April through July.

Applying methods 3 and 4 to the ERA-Interim reanalysis yields a similar seasonal cycle of predictability with maxima in MAMJ. The values, however, are consistently lower in the reanalysis data. This could mean that predictability is overestimated in the models but caution is needed because the observation-based data consist of only one realization while the SINTEX-F calculations are based on ensemble means. 


\section{Tropical Pacific}

\section{a. Equatorial Pacific}

We perform a similar analysis as in section $3 \mathrm{a}$ on the equatorial Pacific. Here, we focus on the variability of surface zonal wind in the Niño-4 region (see Fig. 1 for area definition). The ERA-Interim reanalysis shows two peaks in Niño-4 variance in October and February, whereas variance is lowest in late boreal spring and early summer (Fig. 9a). CTRL captures the seasonal cycle of variability fairly well but underestimates variability in boreal fall and winter. The variance in CTA is very similar to that of CTRL, albeit slightly lower. Only very little variance remains in either CTP or CGL, and all differences pass the $95 \%$ significance test. Using the same method as in section 3a to calculate the deterministic (i.e., SST-forced) component of Niño-4 wind variability, we estimate that, averaged over the whole year, the tropical Pacific contributes $96 \%$ while the tropical Atlantic contributes 5\%. While these numbers roughly add up to $100 \%$ the uncertainty associated with them is likely considerable. It has been shown, for example, that the Indian Ocean also contributes significantly to tropical Pacific variability (Izumo et al. 2010).

The $\mathrm{ACC}^{2}$ of Niño-4 surface zonal wind (respective to ERA-Interim) in CTRL shows high values around 0.8, except for a moderate decline in June (Fig. 9b). The $\mathrm{ACC}^{2}$ in CTA is very similar but slightly lower during most months. Using CTRL as the reference (Fig. 9c) yields very high values around 0.95 in CTA, while CTP and CGL are close to zero.

There is evidence that the Atlantic-Pacific link is dependent on the mean state Atlantic SST (e.g., Rodríguez-Fonseca et al. 2009; Martín-Rey et al. 2014). Since there are significant mean state changes during our study period (1982-2014), due to the Atlantic multidecadal oscillation (AMO) switching sign, it is possible that this affects our results. We have tested this by splitting the time series into the periods 1982-95 (negative AMO) and 1996-2014 (positive AMO) and applying our analysis separately to those. Consistently with Martín-Rey et al. (2014) the analysis suggests a stronger Atlantic-Pacific link for the negative phase of the AMO (not shown). The differences, however, are relatively subtle ( $9 \%$ as opposed to $5 \%$ ) and not statistically significant. Further analysis with idealized SST distributions and longer time series would be required to adequately test for the dependence on background SST.

\section{b. Comparison with alternative estimates of internal variability}

Similarly to section $3 c$, we compare the four different estimates of predictability for the Niño-4 region and plot
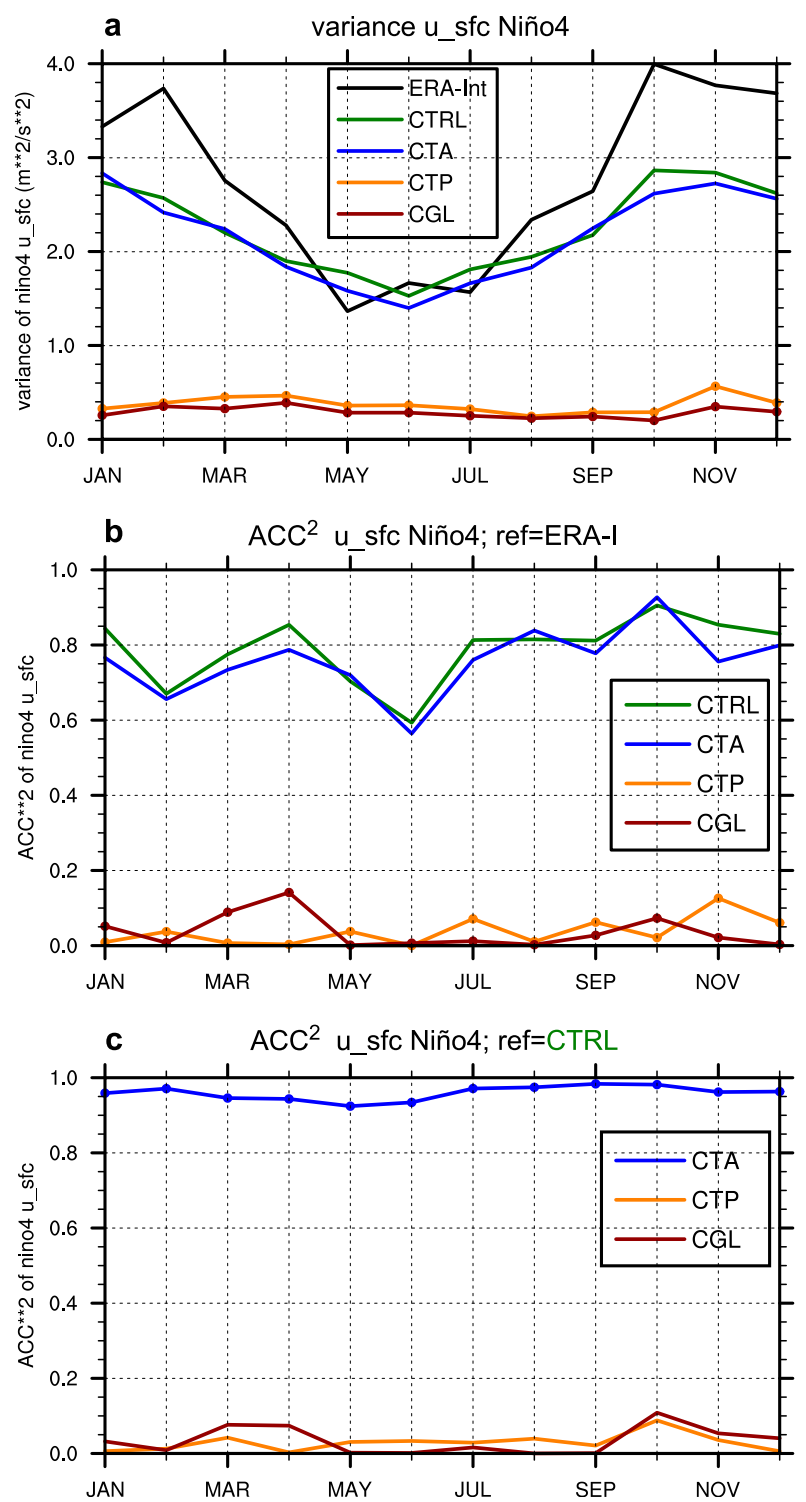

FIG. 9. As in Fig. 2, but for the Niño-4 region.

them in Fig. 10. The SST indices used for the multiple regression are Niño-3.4, the NTA, and the Indian Ocean dipole (IOD) index as defined by Saji et al. (1999). All methods agree fairly well but method 3 (the regression analysis) tends to produce the lowest values, relatively speaking. All four methods give estimates of 0.8 and higher throughout most of the year, although methods 3 and 4 suggest a slight dip in boreal summer.

Applying methods 3 and 4 to the ERA-Interim yields much more cautious estimates of predictability, as was the case for the equatorial Atlantic. Moreover, the reanalysis suggests a stronger seasonality of predictability. The minimum occurs in June, although method 3 has another minimum in February. 


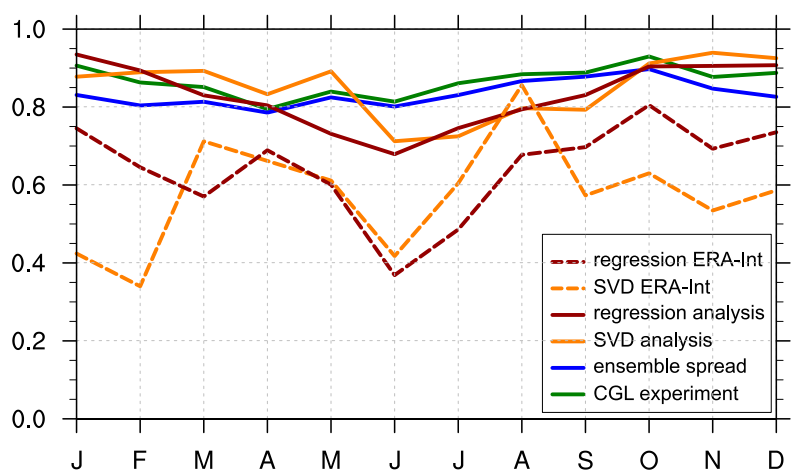

FIG. 10. As in Fig. 8, but for the Niño-4 region.

\section{Link between internal variability and background state}

The internal variability component of equatorial Atlantic surface winds was previously examined by Richter et al. (2014b). They arrived at a much higher estimate of about $65 \%$ as compared to the $32 \%$ obtained here (section 3a). The results of Richter et al. (2014b) were based on a model ensemble of the CMIP5 experiment sstClim, with climatological SST prescribed over the global oceans, similar to our experiment CGL. In difference to CGL, however, the climatological SSTs in sstClim were derived from the preindustrial control experiment (piControl), in which the coupled models are free to evolve. The SST boundary forcing therefore features, to varying degrees, the warm biases typically found in the eastern equatorial and south equatorial Atlantic (Richter et al. 2014a). Several previous studies have suggested a link between mean state SST and atmospheric noise (Lengaigne et al. 2004; Eisenman et al. 2005; Perez et al. 2005; Jin et al. 2007; Kug et al. 2008). This suggests that the high noise estimates of Richter et al. (2014b) may partially be due to the erroneously warm SST in piControl/sstClim. The noise fraction in Richter et al. (2014b) was calculated analogously to method 1 (see section $2 \mathrm{~b})$ as $n f=n /(s+n)$, where $n$ is derived from sstClim, and $s+n$ is derived from piControl. The SST bias leads to an additional noise component, $n_{b}$, that is added to both the numerator and the denominator: $n f^{\prime}=$ $\left(n+n_{b}\right) /\left(s+n+n_{b}\right)$. It can easily be verified that $n f^{\prime}$ is always greater than $n f$ by calculating the difference $n f^{\prime}-$ $n f=n_{b} s /\left[\left(s+n+n_{b}\right)(s+n)\right]$. This is greater than zero since it only contains positive terms.

In a recent study, Richter et al. (2018) analyzed how tropical mean state SST biases influence the ability of a model to reproduce observed surface wind and precipitation anomalies. This was done using a similar experimental setup as in the present study but with mean state biases from a free-running coupled SINTEX-F control simulation added to the CTRL boundary forcing

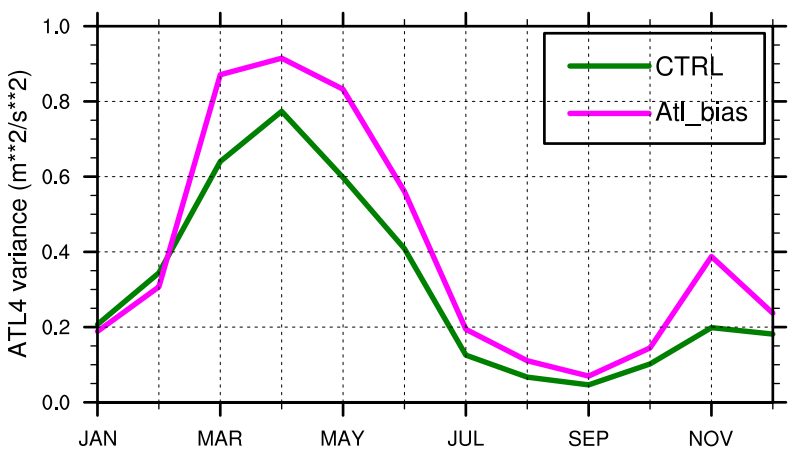

FIG. 11. Ensemble spread (based on nine ensemble members) of surface zonal wind $\left(\mathrm{m}^{2} \mathrm{~s}^{-2}\right)$ in the ATL4 region for CTRL (green line) and Atl_bias (pink line).

in the tropical Atlantic. Thus the SST anomalies in the tropical Atlantic were the same as in the observations but the mean state was different. We use this ninemember experiment (hereafter referred to as Atl_bias) to examine the influence of mean state SST biases on internal variability of surface zonal wind. The analysis in Richter et al. (2018) and in this section are, to some extent, complementary to the ones of Jouanno et al. (2017), who investigated the influence of biased wind forcing on oceanic variability in an OGCM simulation.

The ensemble spread (a measure of the noise) in the ATL4 region is indeed higher in Atl_bias than in CTRL (Fig. 11), particularly in boreal spring (roughly $30 \%$ increase), although none of the differences are significant at the $95 \%$ level. We note the increase is even higher when calculated via method 1 (variance along the time dimension; not shown).

We have seen that westerly wind events in the equatorial Atlantic are associated with a southward shift of the Atlantic ITCZ (Fig. 4). A general link between the strength of surface winds (both in terms of mean and variability) and ITCZ latitude in the equatorial Atlantic has been demonstrated in previous studies (Richter et al. 2014a,b, 2017, 2018). We examine if this link is also valid for the noise (i.e., if the amplitude of the noise depends on ITCZ position). First we inspect to what extent the internal variability of the surface zonal wind and precipitation is collocated in MAM (Fig. 12a). In the tropical Atlantic, the internal variability of precipitation is concentrated in the equatorial Atlantic, in the approximate location of the ITCZ (Fig. 12b). The internal variability of surface zonal wind follows that of precipitation quite closely in the equatorial Atlantic. The close correspondence does not extend to the subtropics, where the wind noise is highest while precipitation noise is generally low. Comparison with the mean precipitation (Fig. 12b) suggests that all three fields are well aligned in the equatorial Atlantic. 


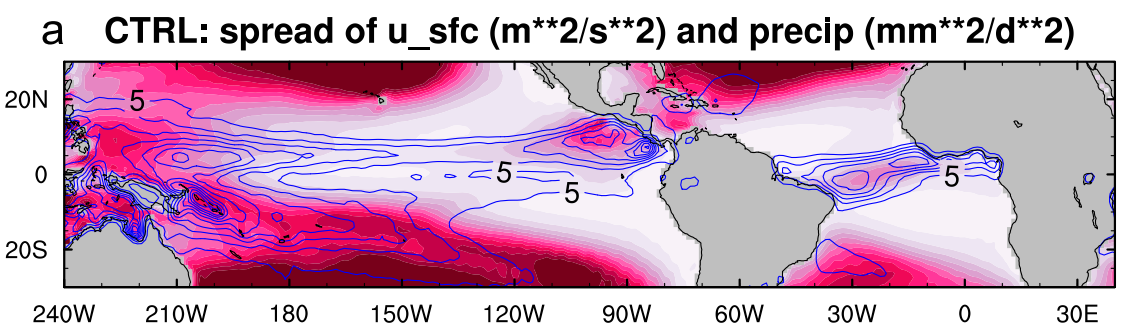

b CTRL: spread of $u_{-} s f c\left(m^{\star \star} 2 / \mathrm{s}^{\star \star} 2\right)$ and mean precip $(\mathrm{mm} / \mathrm{d})$

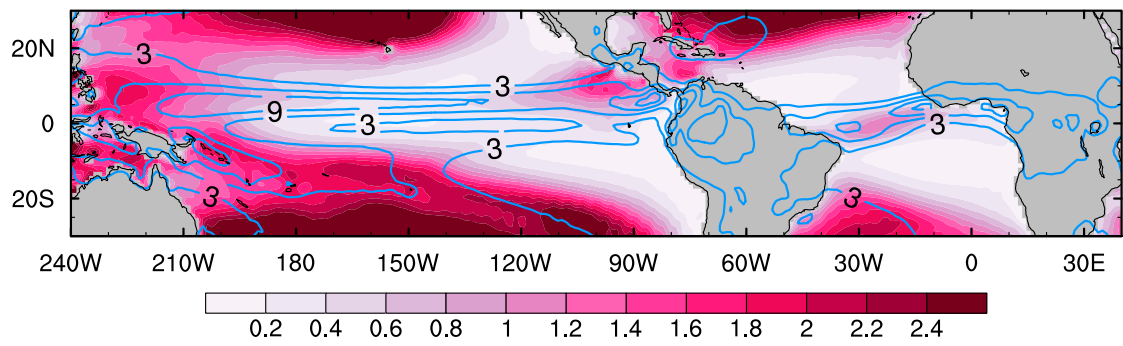

FIG. 12. (a) Ensemble spread of surface zonal wind (shading; $\mathrm{m}^{2} \mathrm{~s}^{-2}$ ) and ensemble spread of precipitation (contours; $\mathrm{mm}^{2} \mathrm{day}^{-2}$ ) in CTRL averaged over March through May (MAM). (b) As in (a), but with contour lines indicating mean precipitation $\left(\mathrm{mm} \mathrm{day}^{-1}\right)$.

In the equatorial Pacific, the correspondence between wind and precipitation noise is less obvious but still suggestive of a link. The four maxima of precipitation noise (one over the far eastern Pacific, three over the Pacific warm pool) are generally collocated with high noise in the surface zonal wind. The mean precipitation also shows some relation to these patterns but is more zonally elongated with less distinct maxima. In particular, the high precipitation over the central equatorial Pacific has no counterpart in the two noise fields.

The results indicate that the mean state does have an impact on atmospheric internal variability and thus probably contributed to the high estimate of internal variability by Richter et al. (2014b). While the earlier estimate likely was too high there are also some uncertainties related to the current estimate. Although forced with observed SST, the SINTEX-F GCM may be subject to precipitation biases that cause it to underestimate internal variability. Estimates from the ERA-Interim (section 3c) support the notion that internal variability in nature is actually higher than estimated by SINTEX-F.

\section{Summary and conclusions}

\section{a. Summary}

We have attempted to quantify the predictable and unpredictable components of interannual surface wind variability in the tropical Atlantic and Pacific. Our analysis mostly relied on sensitivity tests with the
SINTEX-F GCM, in which SST variability was removed in selected regions. Three other methods of estimating internal variability were employed, namely ensemble spread, regression analysis, and SVD analysis. We compared our results from SINTEX-F with estimates derived from the ERA-Interim data.

For the equatorial Atlantic, the model results suggest that, during the season of highest variability (boreal spring and early summer), two-thirds of zonal surface wind variability are determined by the SST distribution and therefore potentially predictable. The remaining third is due to atmospheric noise and therefore unpredictable (on interannual time scales). Of the predictable component, about $65 \%-75 \%$ is due to local (i.e., tropical Atlantic) SST while the rest is due to remote SST, particularly those in the tropical Pacific.

Only about one-third of surface wind speed variability over the subtropical North Atlantic is determined by SST. One sensitivity test (CTP) suggests that this part is almost exclusively due to tropical Pacific SST, while a second one (CTA) suggests that the tropical Atlantic may have a minor contribution.

In the equatorial Pacific Niño-4 region, model analysis suggests high predictability ( $80 \%$ or more) throughout the year. About $95 \%$ of this predictable component is determined by local SST, with the remaining $5 \%$ determined by the tropical Atlantic. The strong influence of SST on equatorial Pacific surface winds explains why prediction systems using SST nudging for ocean initialization can be quite successful in the tropical Pacific 
(Luo et al. 2005; Keenlyside et al. 2005; Zhu et al. 2015, 2017; Doi et al. 2017).

The alternative estimates of internal variability tend to agree rather well with those derived from the sensitivity experiments. Applying the SVD and regression analysis to the ERA-Interim produces estimates that are qualitatively similar to the model analysis but less optimistic.

We find that the internal variability of surface wind in the deep tropics is linked to the mean state, in particular to the location of the ITCZ. This is evident in the Atlantic basin, where there is a close spatial correspondence between the patterns of internal variability and deep convection. The tropical Pacific also shows some evidence of this link but the spatial correspondence is less striking.

\section{b. Conclusions}

The model results indicate a large potentially predictable component of equatorial Atlantic surface winds, with a somewhat lower estimate from the ERAInterim. This, by itself, should bode well for the prospect of skillfully predicting equatorial Atlantic variability. The ability of a model to reproduce equatorial surface winds, however, is only one element of successful prediction. The response of the ocean to the wind forcing has to be captured as well by the models. This response may be deteriorated by mean state biases in the oceanic component (Deppenmeier et al. 2016; Dippe and Greatbatch 2017; Jouanno et al. 2017) and deficiencies in mixing parameterizations. Initialization of the ocean component is another important factor for successful prediction. While some in situ data are available a denser observation network might substantially improve forecast skill. It should also be noted that wind forcing off the equator can influence the equatorial Atlantic (Foltz and McPhaden 2010; Lübbecke and McPhaden 2012; Richter et al. 2013). Thus, off-equatorial wind should also be skillfully predicted, which is a harder problem. In the light of these complications, the current low skill of models in the equatorial Atlantic (Richter et al. 2018) may not be very surprising. We also point out that, while equatorial winds are highly determined by SST, about $35 \%$ of this influence may come from outside the tropical Atlantic. If remote SSTs can influence the equatorial Atlantic surface winds, this might weaken the third component of the Bjerknes feedback (surface wind response to SST anomalies; see section 1) and undermine its effectiveness. This is consistent with the results of Zebiak (1993) and Richter et al. (2017).

Previous studies by the lead author indicated a larger role for atmospheric internal variability in the equatorial Atlantic than reported here. Those results were obtained from an analysis of CMIP5 models that featured the typical warm SST biases in the equatorial Atlantic. In the present study, we use a sensitivity test to show that such SST biases are accompanied by a southward shift of the ITCZ that leads to exaggerated atmospheric variability over the equator. Basing estimates of internal variability on biased models may therefore result in unrealistically high values. Thus caution is needed in the interpretation of such model results. This may extend to other ocean basins as well as the teleconnections between them.

The SST dependence of equatorial Pacific westerly wind bursts has been shown in many previous studies. Here, however, we suggest that the ITCZ position is more important than the mean state SST. While the two variables are certainly related to some extent, there is no one-to-one correspondence between them. The ITCZ position can be influenced by meridional SST gradients in the tropics (e.g., Hastenrath and Heller 1977; Moura and Shukla 1981; Chang et al. 2000) and may even be susceptible to extratropical SST influences (Frierson and Hwang 2012; Fuckar et al. 2013; Marshall et al. 2014). We suggest that the influence of mean state SST on internal surface wind variability is an indirect one that is mediated through the ITCZ location.

Regarding surface wind speed variability in the northern tropical Atlantic, the SINTEX-F results suggest that only $30 \%$ of it is determined by SST, and that $20 \%$ or less of that is due to tropical Atlantic SST. This would seem to leave little leeway for local coupled feedbacks like the WES feedback. There is, however, much uncertainty in our estimate as SST influences from different regions may not add up linearly. Furthermore the low skill of SINTEX-F in reproducing observed surface wind variability in the region may indicate that the model is misrepresenting some of the relevant processes. A more thorough analysis will be needed to confirm the results.

Our results agree with previous studies that suggested a Pacific influence on the tropical Atlantic. This influence is particularly strong in the NTA region but also plays a moderate role in the equatorial Atlantic. A strong influence of the tropical Atlantic on the equatorial Pacific surface winds, on the other hand, is not supported by our results. Consistent with previous studies (Kucharski et al. 2016, and references therein) there is evidence for an influence in boreal summer but it seems to be more moderate than suggested by those studies. In light of the mean state dependence of internal variability it is certainly possible that these results are partially model dependent. There is also the possibility that decadal modulation of the mean state influences 
basin interaction. Thus the sensitivity of the AtlanticPacific link to the mean state is a topic that deserves further attention.

Acknowledgments. The authors thank the three anonymous reviewers for their valuable comments. IR was partially supported by the Japan Society for the Promotion of Science, KAKENHI Grant 18H01281. The SINTEX-F GCM experiments were run on the Earth Simulator at JAMSTEC. We are grateful to Dr. Jing-Jia Luo, Dr. Sebastian Masson, and our European colleagues of INGV/CMCC, L'OCEAN, and MPI for their contribution to developing the prototype of the model.The authors thank Dr. Masami Nonaka for helpful comments on the manuscript.

\section{REFERENCES}

Alessandri, A., A. Borrelli, S. Masina, A. Cherchi, S. Gualdi, A. Navarra, P. Di Pietro, and A. F. Carril, 2010: The INGVCMCC seasonal prediction system: Improved ocean initial conditions. Mon. Wea. Rev., 138, 2930-2952, https://doi.org/ 10.1175/2010MWR3178.1.

Alexander, M. A., I. Bladé, M. Newman, J. R. Lanzante, N.-C. Lau, and J. D. Scott, 2002: The atmospheric bridge: The influence of ENSO teleconnections on air-sea interaction over the global oceans. J. Climate, 15, 2205-2231, https://doi.org/10.1175/15200442(2002)015<2205:TABTIO >2.0.CO;2.

Amaya, D. J., and G. R. Foltz, 2014: Impacts of canonical and Modoki El Niño on tropical Atlantic SST. J. Geophys. Res. Oceans, 119, 777-789, https://doi.org/10.1002/ 2013JC009476.

_ - M. J. DeFlorio, A. J. Miller, and S.-P. Xie, 2017: WES feedback and the Atlantic Meridional Mode: Observations and CMIP5 comparisons. Climate Dyn., 49, 1655-1679, https:// doi.org/10.1007/s00382-016-3411-1.

Bjerknes, J., 1969: Atmospheric teleconnections from the equatorial Pacific. Mon. Wea. Rev., 97, 163-172, https://doi.org/ 10.1175/1520-0493(1969)097<0163:ATFTEP > 2.3.CO;2.

Chang, P., L. Ji, and H. Li, 1997: A decadal climate variation in the tropical Atlantic Ocean from thermodynamic air-sea interactions. Nature, 385, 516-518, https://doi.org/10.1038/ $385516 \mathrm{a} 0$

— local sea surface temperatures on atmospheric circulation over the tropical Atlantic sector. J. Climate, 13, 2195-2216, https:// doi.org/10.1175/1520-0442(2000)013<2195: TEOLSS $>2.0 . \mathrm{CO} ; 2$

_ L. Ji, and R. Saravanan, 2001: A hybrid coupled model study of the tropical Atlantic variability. J. Climate, 14, 361-390, https://doi.org/10.1175/1520-0442(2001)013<0361: AHCMSO $>2.0 . \mathrm{CO} ; 2$.

_, Y. Fang, R. Saravanan, L. Ji, and H. Seidel, 2006: The cause of the fragile relationship between the Pacific El Niño and the Atlantic Niño. Nature, 443, 324-328, https://doi.org/10.1038/ nature 05053 .

Chiodi, A. M., and D. E. Harrison, 2017: Observed El Nino SSTA development and the effects of easterly and westerly wind events in 2014/15. J. Climate, 30, 1505-1519, https://doi.org/ 10.1175/JCLI-D-16-0385.1.
Davey, M. K., and Coauthors, 2002: STOIC: A study of coupled model climatology and variability in tropical ocean regions. Climate Dyn., 18, 403-420, https://doi.org/10.1007/s00382-001-0188-6.

DelSole, T., and J. Shukla, 2010: Model fidelity versus skill in seasonal forecasting. J. Climate, 23, 4794-4806, https://doi.org/ 10.1175/2010JCLI3164.1.

Deppenmeier, A.-L., R. J. Haarsma, and W. Hazeleger, 2016: The Bjerknes feedback in the tropical Atlantic in CMIP5 models. Climate Dyn., 47, 2691-2707, https://doi.org/10.1007/s00382016-2992-z.

Ding, H., N. S. Keenlyside, and M. Latif, 2012: Impact of the equatorial Atlantic on the El Niño southern oscillation. Climate Dyn., 38, 1965-1972, https://doi.org/10.1007/s00382-0111097-y.

Dippe, T., R. J. Greatbatch, and D. Hui, 2017: On the relationship between Atlantic Niño variability and ocean dynamics. Climate Dyn., 51, 597-612, https://doi.org/10.1007/s00382-0173943-z.

Doi, T., A. Storto, S. K. Behera, A. Navarra, and T. Yamagata, 2017: Improved prediction of the Indian Ocean dipole mode by use of subsurface ocean observations. J. Climate, 30, 79537970, https://doi.org/10.1175/JCLI-D-16-0915.1.

Eisenman, I., L. Yu, and E. Tziperman, 2005: Westerly wind bursts: ENSO's tail rather than the dog? J. Climate, 18, 5224-5238, https://doi.org/10.1175/JCLI3588.1.

Enfield, D. B., and D. A. Mayer, 1997: Tropical Atlantic SST variability and its relation to El Niño-Southern Oscillation. J. Geophys. Res., 102, 929-945, https://doi.org/10.1029/ 96JC03296.

Foltz, G. R., and M. J. McPhaden, 2010: Abrupt equatorial waveinduced cooling of the Atlantic cold tongue in 2009. Geophys. Res. Lett., 37, L24605, https://doi.org/10.1029/2010GL045522.

Frierson, D. M. W., and Y.-T. Hwang, 2012: Extratropical influence on ITCZ shifts in slab ocean simulations of global warming. J. Climate, 25, 720-733, https://doi.org/10.1175/JCLI-D-1100116.1.

Fuckar, N. S., S.-P. Xie, R. Farneti, E. Maroon, and D. M. W. Frierson, 2013: Influence of the extratropical ocean circulation on the intertropical convergence zone in an idealized coupled general circulation model. J. Climate, 26, 4612-4629, https:// doi.org/10.1175/JCLI-D-12-00294.1.

García-Serrano, J., C. Cassou, H. Douville, A. Giannini, and F. J. Doblas-Reyes, 2017: Revisiting the ENSO teleconnection to the tropical North Atlantic. J. Climate, 30, 6945-6957, https:// doi.org/10.1175/JCLI-D-16-0641.1.

Gualdi, S., A. Navarra, E. Guilyardi, and P. Delecluse, 2003: Assessment of the tropical Indo-Pacific climate in the SINTEX CGCM. Ann. Geophys., 46, 1-26, https://doi.org/10.4401/ag3385.

Ham, Y.-G., J.-S. Kug, J.-Y. Park, and F.-F. Jin, 2013: Sea surface temperature in the north tropical Atlantic as a trigger for El Niño/Southern Oscillation events. Nat. Geosci., 6, 112-116, https://doi.org/10.1038/ngeo1686.

Hastenrath, S., and L. Heller, 1977: Dynamics of climatic hazards in northeast Brazil. Quart. J. Roy. Meteor. Soc., 103, 77-92, https://doi.org/10.1002/qj.49710343505.

Huang, B., 2004: Remotely forced variability in the tropical Atlantic Ocean. Climate Dyn., 23, 133-152, https://doi.org/ 10.1007/s00382-004-0443-8.

, P. S. Schopf, and Z. Pan, 2002: The ENSO effect on the tropical Atlantic variability: A regionally coupled model study. Geophys. Res. Lett., 29, 2039, https://doi.org/10.1029/ 2002GL014872. 
Imada, Y., H. Tatebe, M. Watanabe, M. Ishii, and M. Kimoto, 2016: South Pacific influence on the termination of El Niño in 2014. Sci. Rep., 6, 30341, https://doi.org/10.1038/srep30341.

Izumo, T., and Coauthors, 2010: Influence of the state of the Indian Ocean dipole of the following year's El Niño. Nat. Geosci., 3, 168-172, https://doi.org/10.1038/ngeo760.

Ji, M., and A. Leetmaa, 1997: Impact of data assimilation on ocean initialization and El Niño prediction. Mon. Wea. Rev., 125, 742-753, https://doi.org/10.1175/1520-0493(1997)125<0742: IODAOO $>2.0 . \mathrm{CO} ; 2$.

Jin, F.-F., 1997: An equatorial ocean recharge paradigm for ENSO. Part I: Conceptual model. J. Atmos. Sci., 54, 811-829, https:// doi.org/10.1175/1520-0469(1997)054<0811:AEORPF> 2.0.CO;2.

— L. Lin, A. Timmermann, and J. Zhao, 2007: Ensemble-mean dynamics of the ENSO recharge oscillator under statedependent stochastic forcing. Geophys. Res. Lett., 34, L03807, https://doi.org/10.1029/2006GL027372.

Jouanno, J., O. Hernandez, and E. Sanchez-Gomez, 2017: Equatorial Atlantic interannual variability and its relation to dynamic and thermodynamic processes. Earth Syst. Dyn., 8, 1061-1069, https://doi.org/10.5194/esd-8-1061-2017.

Kajtar, J. B., A. Santoso, M. H. England, and W. Cai, 2017: Tropical climate variability: Interactions across the Pacific, Indian, and Atlantic Oceans. Climate Dyn., 48, 2173-2190, https://doi.org/10.1007/s00382-016-3199-z.

Keenlyside, N. S., and M. Latif, 2007: Understanding equatorial Atlantic interannual variability. J. Climate, 20, 131-142, https://doi.org/10.1175/JCLI3992.1.

,- M. Botzet, J. Jungclaus, and U. Schulzweida, 2005: A coupled method for initializing El Niño Southern Oscillation forecasts using sea surface temperature. Tellus, 57A, 340-356, https://doi.org/10.1111/j.1600-0870.2005.00107.x.

,- H. Ding, and M. Latif, 2013: Potential of equatorial Atlantic variability to enhance El Niño prediction. Geophys. Res. Lett., 40, 2278-2283, https://doi.org/10.1002/grl.50362.

Kosaka, Y., 2018: Slow warming and the ocean see-saw. Nat. Geosci., 11, 12-13, https://doi.org/10.1038/s41561-017-0038-8.

— equatorial Pacific surface cooling. Nature, 501, 403-407, https://doi.org/10.1038/nature12534.

Kucharski, F., and Coauthors, 2016: The teleconnection of the tropical Atlantic to Indo-Pacific sea surface temperatures on inter-annual to centennial time scales: A review of recent findings. Atmosphere, 7, 29, https://doi.org/10.3390/ atmos7020029.

Kug, J.-S., F.-F. Jin, K. P. Sooraj, and I.-S. Kang, 2008: Statedependent atmospheric noise associated with ENSO. Geophys. Res. Lett., 35, L05701, https://doi.org/10.1029/ 2007 GL032017.

Kumar, A., and J. Zhu, 2018: Spatial variability in seasonal prediction skill of SSTs: Inherent predictability or forecast errors? J. Climate, 31, 613-621, https://doi.org/10.1175/JCLI-D-170279.1.

Larson, S. M., B. P. Kirtman, and D. J. Vimont, 2017: A framework to decompose wind-driven biases in climate models applied to CCSM/CESM in the eastern Pacific. J. Climate, 30, 8763-8782, https://doi.org/10.1175/JCLI-D-17-0099.1.

Latif, M., and A. Grötzner, 2000: The equatorial Atlantic oscillation and its response to ENSO. Climate Dyn., 16, 213-218, https://doi.org/10.1007/s003820050014.

Lee, J.-Y., and Coauthors, 2010: How are seasonal prediction skills related to models' performance on mean state and annual cycle? Climate Dyn., 35, 267-283, https://doi.org/10.1007/ s00382-010-0857-4.

Lee, S.-K., D. B. Enfield, and C. Wang, 2008: Why do some El Niños have no impact on tropical North Atlantic SST? Geophys. Res. Lett., 35, L16705, https://doi.org/10.1029/ 2008 GL034734.

Lengaigne, M., E. Guilyardi, J. P. Boulanger, C. Menkes, P. Delecluse, P. Inness, J. Cole, and J. Slingo, 2004: Triggering El Niño by westerly wind events in a coupled general circulation model. Climate Dyn., 23, 601-620, https://doi.org/ 10.1007/s00382-004-0457-2.

Levine, A. F. Z., and F. F. Jin, 2010: Noise-induced instability in the ENSO recharge oscillator. J. Atmos. Sci., 67, 529-542, https:// doi.org/10.1175/2009JAS3213.1.

Li, X., S.-P. Xie, S. T. Gille, and C. Yoo, 2016: Atlantic-induced pan-tropical climate change over the past three decades. Nat. Climate Change, 6, 275-279, https://doi.org/10.1038/ nclimate 2840.

Lübbecke, J. F., and M. J. McPhaden, 2012: On the inconsistent relationship between Pacific and Atlantic Niños. J. Climate, 25, 4294-4303, https://doi.org/10.1175/JCLI-D-11-00553.1.

Luo, J. J., S. Masson, S. K. Behera, P. Delecluse, S. Gualdi, A. Navarra, and T. Yamagata, 2003: South Pacific origin of the decadal ENSO-like variation as simulated by a coupled GCM. Geophys. Res. Lett., 30, 2250, https://doi.org/10.1029/ 2003 GL018649.

,-- , E. Roeckner, G. Madec, and T. Yamagata, 2005: Reducing climatology bias in an ocean-atmosphere CGCM with improved coupling physics. J. Climate, 18, 2344-2360, https:// doi.org/10.1175/JCLI3404.1.

Madec, G., P. Delecluse, M. Imbard, and C. Levy, 1998: OPA 8.1 ocean general circulation model reference manual. Note du Pole de Modelisation 11, IPSL, $91 \mathrm{pp}$.

Magnusson, L., M. Alonso-Balmaseda, S. Corti, F. Molteni, and T. Stockdale, 2013: Evaluation of forecast strategies for seasonal and decadal forecasts in presence of systematic model errors. Climate Dyn., 41, 2393-2409, https://doi.org/10.1007/ s00382-012-1599-2.

Manganello, J. V., and B. Huang, 2009: The influence of systematic errors in the Southeast Pacific on ENSO variability and prediction in a coupled GCM. Climate Dyn., 32, 1015-1034, https://doi.org/10.1007/s00382-008-0407-5.

Marshall, J., A. Donohoe, D. Ferreira, and D. McGee, 2014: The ocean's role in setting the mean position of the inter-tropical convergence zone. Climate Dyn., 42, 1967-1979, https:// doi.org/10.1007/s00382-013-1767-z.

Martín-Rey, M., B. Rodríguez-Fonseca, I. Polo, and F. Kucharski, 2014: On the Atlantic-Pacific Niños connection: A multidecadal modulated mode. Climate Dyn., 43, 3163-3178, https://doi.org/10.1007/s00382-014-2305-3.

- I. Polo, B. Rodríguez-Fonseca, T. Losada, and A. Lazar, 2018: Is there evidence of changes in tropical Atlantic variability modes under AMO phases in the observational record? J. Climate, 31, 515-536, https://doi.org/10.1175/JCLI-D-160459.1.

McGregor, S., A. Timmermann, M. F. Stuecker, M. H. England, M. Merrifield, F.-F. Jin, and Y. Chikamoto, 2014: Recent Walker circulation strengthening and Pacific cooling amplified by Atlantic warming. Nat. Climate Change, 4, 888-892, https:// doi.org/10.1038/nclimate2330.

McPhaden, M. J., 2015: Playing hide and seek with El Niño. Nat. Climate Change, 5, 791-795, https://doi.org/10.1038/ nclimate2775. 
Moore, A. M., and R. Kleeman, 1999: Stochastic forcing of ENSO by the intraseasonal oscillation. J. Climate, 12, 1199-1220, https://doi.org/10.1175/1520-0442(1999)012<1199:SFOEBT> 2.0.CO;2.

Moura, A., and J. Shukla, 1981: On the dynamics of droughts in northeast Brazil: Observations, theory, and numerical experiments with a general circulation model. J. Atmos. Sci., 38, 2653-2675, https://doi.org/10.1175/1520-0469(1981)038<2653: OTDODI $>2.0 . \mathrm{CO} ; 2$.

Neelin, J. D., D. S. Battisti, A. C. Hirst, F.-F. Jin, Y. Wakata, T. Yamagata, and S. Zebiak, 1998: ENSO theory. J. Geophys. Res., 103, 14 261-14 290, https://doi.org/10.1029/97JC03424.

Nnamchi, H., J. Li, F. Kucharski, I. Kang, N. S. Keenlyside, P. Chang, and R. Farneti, 2015: Thermodynamic controls of the Atlantic Niño. Nat. Commun., 6, 8895, https://doi.org/ 10.1038/ncomms9895.

Perez, C. L., A. M. Moore, J. Zavala-Garay, and R. Kleeman, 2005: A comparison of the influence of additive and multiplicative stochastic forcing on a coupled model of ENSO. J. Climate, 18, 5066-5085, https://doi.org/10.1175/JCLI3596.1.

Reynolds, R. W., N. A. Rayner, T. M. Smith, D. C. Stokes, and W. Wang, 2002: An improved in situ and satellite SST analysis for climate. J. Climate, 15, 1609-1625, https://doi.org/10.1175/ 1520-0442(2002)015<1609:AIISAS > 2.0.CO;2.

Richter, I., and S.-P. Xie, 2008: On the origin of equatorial Atlantic biases in coupled general circulation models. Climate Dyn., 31, 587-598, https://doi.org/10.1007/s00382-008-0364-z.

—, S. K. Behera, Y. Masumoto, B. Taguchi, H. Sasaki, and T. Yamagata, 2013: Multiple causes of interannual sea surface temperature variability in the equatorial Atlantic Ocean. Nat. Geosci., 6, 43-47, https://doi.org/10.1038/ngeo1660.

— - S.-P. Xie, S. K. Behera, T. Doi, and Y. Masumoto, 2014a: Equatorial Atlantic variability and its relation to mean state biases in CMIP5. Climate Dyn., 42, 171-188, https://doi.org/ 10.1007/s00382-012-1624-5.

_ S. K. Behera, T. Doi, B. Taguchi, Y. Masumoto, and S.-P. Xie, 2014b: What controls equatorial Atlantic winds in boreal spring? Climate Dyn., 43, 3091-3104, https://doi.org/10.1007/ s00382-014-2170-0.

_ , and Coauthors, 2016: An overview of coupled GCM biases in the tropics. Indo-Pacific Climate Variability and Predictability, T. Yamagata and S. K. Behera, Eds., World Scientific Series on Asia-Pacific Weather and Climate, Vol. 8, World Scientific 213-263, https://doi.org/10.1142/9789814696623_0008.

—, S.-P. Xie, Y. Morioka, T. Doi, B. Taguchi, and S. K. Behera, 2017: Phase locking of equatorial Atlantic variability through the seasonal migration of the ITCZ. Climate Dyn., 48, 36153629, https://doi.org/10.1007/s00382-016-3289-y.

_ T. Doi, S. K. Behera, and N. Keenlyside, 2018: On the link between mean state biases and prediction skill in the tropics: An atmospheric perspective. Climate Dyn., 50, 3355-3374, https://doi.org/10.1007/s00382-017-3809-4.

Rodríguez-Fonseca, B., I. Polo, J. García-Serrano, T. Losada, E. Mohino, C. R. Mechoso, and F. Kucharski, 2009: Are Atlantic Niños enhancing Pacific ENSO events in recent decades? Geophys. Res. Lett., 36, L20705, https://doi.org/ 10.1029/2009GL040048.

Roeckner, E., and Coauthors, 1996: The atmospheric general circulation model ECHAM-4: Model description and simulation of present-day climate. Max Planck Institute for Meteorology Rep. 218, 90 pp., http://www.mpimet.mpg.de/ fileadmin/publikationen/Reports/MPI-Report_218.pdf.

Saji, H. N., B. N. Goswami, P. N. Vinayachandran, and T. Yamagata, 1999: A dipole mode in the tropical Indian Ocean. Nature, 401, 360-363, https://doi.org/10.1038/ 43854

Sasaki, W., T. Doi, K. J. Richards, and Y. Masumoto, 2014: Impact of the equatorial Atlantic sea surface temperature on the tropical Pacific in a CGCM. Climate Dyn., 43, 2539-2552, https://doi.org/10.1007/s00382-014-2072-1.

Terray, P., S. Masson, C. Prodhomme, M. K. Roxy, and K. P. Sooraj, 2016: Impacts of Indian and Atlantic oceans on ENSO in a comprehensive modeling framework. Climate Dyn., 46, 2507-2533, https://doi.org/10.1007/s00382-015-2715-x.

Tompkins, A. M., and L. Feudale, 2010: Seasonal ensemble predictions of West African monsoon precipitation in the ECMWF System 3 with a focus on the AMMA special observing period in 2006. Wea. Forecasting, 25, 768-788, https:// doi.org/10.1175/2009WAF2222236.1.

Valcke, S., L. Terray, and A. Piacentini, 2000: The OASIS coupler user guide version 2.4. Tech. Rep. TR/CGMC/00-10, CERFACS, $85 \mathrm{pp}$.

Wang, C., 2006: An overlooked feature of tropical climate: InterPacific-Atlantic variability. Geophys. Res. Lett., 33, L12702, https://doi.org/10.1029/2006GL026324.

Wang, L., J.-Y. Yu, and H. Paek, 2017: Enhanced biennial variability in the Pacific due to Atlantic capacitor effect. Nat. Commun., 8, 14887, https://doi.org/10.1038/ncomms14887.

Xie, S.-P., and S. G. H. Philander, 1994: A coupled oceanatmosphere model of relevance to the ITCZ in the eastern Pacific. Tellus, 46A, 340-350, https://doi.org/10.3402/ tellusa.v46i4.15484.

Zebiak, S. E., 1993: Air-sea interaction in the equatorial Atlantic region. J. Climate, 6, 1567-1586, https://doi.org/10.1175/15200442(1993)006<1567:AIITEA > 2.0.CO;2.

Zheng, F., and J. Zhu, 2015: Roles of initial ocean surface and subsurface states on successfully predicting 2006-2007 El Niño with an intermediate coupled model. Ocean Sci., 11, 187-194, https://doi.org/10.5194/os-11-187-2015.

Zhu, J., A. Kumar, H. Wang, and B. Huang, 2015: Sea surface temperature predictions in NCEP CFSv2 using a simple ocean initialization scheme. Mon. Wea. Rev., 143, 3176-3191, https:// doi.org/10.1175/MWR-D-14-00297.1.

B. Huang, M. A. Balmaseda, Z.-Z. Hu, L. Marx, and J. L. Kinter III, 2016: The role of off-equatorial surface temperature anomalies in the $2014 \mathrm{El}$ Niño prediction. Sci. Rep., 6, 19677, https://doi.org/10.1038/srep19677.

, — _ H. C. Lee, and H. Wang, 2017: Seasonal predictions using a simple ocean initialization scheme. Climate Dyn., 49, 3989-4007, https://doi.org/10.1007/s00382-017-3556-6. 